\title{
HEALTH CARE, HEALTH INSURANCE, AND THE RELATIVE INCOME OF THE ELDERLY AND NONELDERLY
}

\author{
Gary Burtless and Pavel Svaton* \\ CRR WP 2009-10 \\ Released: March 2009 \\ Draft Submitted: January 2009
}
Center for Retirement Research at Boston College
Hovey House
140 Commonwealth Avenue
Chestnut Hill, MA 02467
Tel: 617-552-1762 Fax: 617-552-0191

\begin{abstract}
* Gary Burtless is the John C. and Nancy D. Whitehead Chair in Economic Studies at the Brookings Institution. Pavel Svaton is a senior research assistant at The Brookings Institution. The research reported herein was performed under a grant from the U.S. Social Security Administration (SSA) funded as part of the Retirement Research Consortium (RRC). The findings and conclusions are solely those of the authors and do not represent the views of SSA, any agency of the Federal Government, the RRC, or the Brookings Institution.

(C) 2009, by Gary Burtless and Pavel Svaton. All rights reserved. Short sections of text, not to exceed two paragraphs, may be quoted without explicit permission provided that full credit, including (C) notice, is given to the source.
\end{abstract}




\section{About the Center for Retirement Research}

The Center for Retirement Research at Boston College, part of a consortium that includes parallel centers at the University of Michigan and the National Bureau of Economic Research, was established in 1998 through a grant from the Social Security Administration. The Center's mission is to produce first-class research and forge a strong link between the academic community and decision makers in the public and private sectors around an issue of critical importance to the nation's future. To achieve this mission, the Center sponsors a wide variety of research projects, transmits new findings to a broad audience, trains new scholars, and broadens access to valuable data sources.

\section{Center for Retirement Research at Boston College}

Hovey House

140 Commonwealth Avenue

Chestnut Hill, MA 02467

phone: 617-552-1762 fax: 617-552-0191

e-mail: crr@bc.edu

www.bc.edu/crr

Affiliated Institutions:

The Brookings Institution

Massachusetts Institute of Technology

Syracuse University

Urban Institute 


\begin{abstract}
Cash income offers an incomplete picture of the resources available to finance household consumption. Most American families are covered by an insurance plan that pays for some or all of the health care they consume. Only a comparatively small percentage of families pay for the full cost of this insurance out of their cash incomes. As health care has claimed a growing share of consumption, the percentage of care that is financed out of household incomes has declined. Because health care consumption is more important for some groups in the population than others, the growth in spending and changes in the payment system for medical care have reduced the value of standard income measures for assessing relative incomes across age groups and across the income distribution. More than a seventh of total personal consumption now consists of health care that is purchased with government insurance and employer contributions to employee health plans. In this paper we combine health care spending and insurance reimbursement data in the Medical Expenditure Panel Study with cash and noncash income data in the Current Population Survey to assess the impact of health insurance on the distribution of income and, in particular, on the age profile of income. Our estimates imply that gross money income and disposable cash and near-cash income significantly understate the resources available to finance household purchases. The estimates imply that a more complete measure of resources would show less inequality than the income measures that are currently used. The addition of estimates of the value of health insurance to countable incomes reduces measured inequality in the population and the income gap between young and old. Standard income measures imply that households with an aged household head have significantly lower average and median incomes than households with a head who is less than 55. In contrast, an income definition that includes the value of health insurance implies that aged households have higher incomes than households with a nonaged head.
\end{abstract}




\section{Introduction}

THE GROWTH OF HEALTH CONSUMPTION has had a sizeable and largely unexamined impact on the U.S. income distribution. Americans' consumption of medical goods and services represents a growing percentage of their total consumption. Much of this spending is excluded from standard measures of money income and household well-being. When the Census Bureau calculates median income or changes in the shape of the household income distribution, its standard measure of income includes only money income sources, such as wages, selfemployment earnings, social security benefits, and interest and dividend payments. The money income measure excludes the consumption households enjoy when their employers and the government pay for part or all of their health care. This measurement problem was minor when employer premiums and government health benefits accounted for a small fraction of total consumption, as was the case before 1960. It represents a much bigger problem when these funding sources pay for more than a seventh of total consumption, as is the case today. Actual household spending on medical bills and health insurance premiums similarly provides an unreliable indicator of the health care consumption enjoyed, on average, by people who are covered by a group health plan. Some health consumption is financed with employer contributions to employee health plans, and almost half of health care consumption is financed with government-provided insurance, primarily medicare and medicaid.

In this paper we develop and examine alternative measures of income that combine estimates of households' annual cash income and the health care consumption they obtain that is not financed out of current cash income. The Census Bureau has developed and published expanded income measures that include the insurance value of major kinds of government and employer-provided health insurance (U.S. Bureau of the Census 1993). We extend the earlier Census analysis by examining the actual distribution of health care consumption and health care financing across U.S. households. In addition, we analyze the relationship between health consumption and insurance reimbursement patterns, on the one hand, and age and position in the income distribution, on the other.

The U.S. national income and product accounts (NIPA) show that an increasing percentage of health care consumption is financed with money that is not counted in standard measures of household income. Using detailed information on household health care 
consumption, health insurance coverage, and out-of-pocket spending on medical care and health insurance in the Medical Expenditure Panel Survey (MEPS), we can make good estimates of the portion of health consumption that is financed out of a household's own income and the fraction of care that is financed by someone else. Health care financed by someone else represents an addition to a household's claim over resources that is not included in standard Census Bureau measures of household income. How big are these claims? How are they distributed across young and old and among people at different positions in the income distribution? Because aged Americans consume a disproportionate share of health care goods and services, and because they receive generously subsidized insurance under public programs, their cash incomes provide a particularly misleading picture of their claims on real resources.

The findings of the analysis can be summarized briefly. Using the Census Bureau's estimates of the insurance value of medicare, medicaid, and employer contributions to employee health plans, it appears that the standard money income statistics understate true income by more than 10 percent, with a much larger understatement for the population that is 65 or older. Because the Census Bureau's estimates of insurance value are much more equal than disposable incomes, the Gini coefficient of income inequality would fall substantially if the Bureau's estimates of insurance value were added to money income. The gross incomes of Americans in households headed by a person under 65 would increase about 8.2 percent and the incomes of households headed by someone past 65 would increase slightly more than 37 percent, significantly improving the relative income position of the elderly. The health spending reports in the MEPS do not show such a large effect of subsidized health insurance on the relative income standing of the aged. The estimated difference between household spending on health and household consumption of health care that is observed in the MEPS sample is smaller than the Census Bureau's estimates of insurance value. If we subtract MEPS households' out-ofpocket spending on health care and insurance premiums from their total consumption of health care, the difference represents a claim on resources that is not financed out of household income. Based on interview data obtained in the 2001-2005 MEPS panels, it appears that these claims represent almost 7 percent of household money income. Not surprisingly, there are wide disparities in these claims across households. If the claims were added to disposable cash incomes, Americans who live in households headed by an aged person would see their measured incomes rise 29 percent, but the nonaged would see their incomes rise by only about 5 percent. 
Including these claims in measured income would reduce inequality, but by a smaller percentage than including the Census Bureau's estimate of the insurance value of government and employer provided insurance. Our estimates show that the income adjustment needed to reflect the value of health insurance represents a growing percentage of money income over the 10 years in our analysis period.

The remainder of the paper is organized as follows. The next section presents statistics on aggregate consumption and health care purchases that show the importance of third-party payments for medical care in overall consumption and income. The following section describes the health consumption and insurance data available in the MEPS household file and shows how these data can be used to calculate the net income gains that individual households obtain from their insurance coverage. Section 4 analyzes the health consumption and insurance reimbursement patterns in the MEPS survey to determine the income distributional effects of the U.S. health insurance system. The fifth section considers the implications of health insurance for calculating average income replacement rates that the working population receives as it moves from paid employment into retirement. The following section analyzes experimental income estimates developed by the Census Bureau that include the value of government and employerprovided insurance in consumer incomes. These estimates are tabulated to see the effects of including insurance value in the measure of household income. Section 7 then compares the estimates based on the MEPS survey with the Census Bureau estimates of insurance value and shows the impact of the two sets of estimates on the age distribution of U.S. income. The paper concludes with a brief description of implications of the study for measuring the shape and trend of the U.S. income distribution.

\section{Health Care Consumption and Personal Income}

In 1960 medical spending accounted for less than 7 percent of total personal consumption. By 2007 this fraction had risen to almost 21 percent. Strikingly, however, relatively little of the increase in health spending was financed directly out of household budgets. Between 1960 and 2007 the proportion of health spending paid out of public budgets more than doubled, and the fraction financed through third-party payments from private health insurers increased substantially. The actual fraction of health care costs paid as out-of-pocket payments by households fell by approximately one-third between 1960 and 2007 (Centers for Medicare and Medicaid Services, Office of the Actuary, 2008). In spite of the dramatic increase in 
Americans' health care consumption, a smaller percentage of household expenditures is now devoted to medical care, including health insurance premiums, than was the case in $1960 .{ }^{1}$

As a result of the dramatic rise in third-party payments for medical care, people in many households consume substantially more health services than they could afford if they had to pay for these services out of current income and savings. The personal incomes of these health care consumers thus give a substantial understatement of their actual or potential consumption of goods and services. Of course, many consumers face unusually high health costs in comparison to their incomes. Nonetheless, the rising cost and utilization of health care and the wide disparities in health consumption across the population mean that standard measures of personal income give a misleading picture of Americans' capacity to consume goods and services.

NIPA statistics on personal income and consumption offer an indication of the rising importance of health care consumption and third-party medical payments in the consumption of American families. In 2007 personal consumption of medical goods and services, including the cost of administering the health insurance system, accounted for a little more than one-fifth of total U.S. personal consumption according to the NIPA (see Figure 1). This is very close to the combined share of personal health consumption and the administrative cost of health insurance as estimated in the National Health Expenditure Accounts (NHEA). ${ }^{2}$ Most personal health care consumption and a large percentage of the administrative cost of the health insurance system are financed with government outlays and employer contributions to employee health plans. Only a comparatively small fraction of these outlays is financed directly out of household budgets. The 2007 national health accounts show, for example, that about 14 percent of personal health care is financed with out-of-pocket consumer payments. The other 86 percent is paid with public and private health insurance and direct provision of services by employers, public hospitals and clinics, and philanthropic institutions. Of course, consumers must pay for part of the cost of health insurance with out-of-pocket premium payments, and these premiums must be paid out of

\footnotetext{
${ }^{1}$ In the 1960-61 Consumer Expenditure Survey, 6.7 percent of household expenditures was devoted to health care consumption; in the 2006 Survey, the share devoted to health care was just 5.7 percent (Jacobs and Shipp, 1990, p. 21; and < ftp://ftp.bls.gov/pub/special.requests/ce/standard/ y0006/ multiyr.txt> [accessed on May 15, 2008]).

2 The NHEA, which are estimated and published by the Center for Medicaid and Medicare Services, show somewhat higher estimates of total spending on personal health care and health insurance administration for years before 1990 (see Figure 1). Nonetheless, the long-term trends in personal health
} 
household budgets. Even taking the premium payments into account, however, consumers pay for only about one-quarter of the total cost of the health care they receive. Roughly three quarters personal health care consumption and the administration of the health insurance system is financed out of government budgets, employer contributions to employee health plans, and philanthropy.

The percentage of health care paid out of household budgets has declined over time. In 1960 consumers paid for almost 60 percent of the cost of personal health care and health insurance administration through out-of-pocket payments to health care providers and insurers. The rise of employer-based and government-provided insurance has sharply reduced the proportion of care that must be paid directly by consumers.

The standard money income statistics published by the Census Bureau do not include either employer contributions to employee health plans or government payments for personal health care in the definition of household income. The main Census Bureau income definition ("money income") focuses on cash income directly received by households, a measure that is closely related to the income that would be reported on tax returns. Figure 2 shows employer and government payments for personal health care and the administration of the health insurance system, measured as a percent of total personal consumption and household money income. ${ }^{3}$ The estimates exclude the portion of personal health care that is financed out of households' money income, that is, with out-of-pocket payments for care and health insurance premiums. Personal consumption expenditures are reported directly in the NIPA statistics (in NIPA Table 1.1.5). Estimates of aggregate money income are more difficult to derive from the NIPA tables because the conceptual basis of the NIPA definition of personal income differs from that of the Census Bureau definition of money income. Previous papers have described methods for converting NIPA income statistics into a series that reflects the Census Bureau concept of money income (Roemer 2000; Ruser, Pilot, and Nelson 2004; and Bosworth, Burtless, and Anders 2007). The estimates of household money income used in Figure 2 are based on those methods.

consumption and the cost of the health insurance system are similar in the NIPA and national health expenditure statistics.

3 The estimate of government payments for personal health care is net of consumers' premium payments for coverage under the government insurance plans. Thus, we subtract premium payments for Part B of medicare from medicare benefit outlays in order to calculate the net health consumption that is financed by government payments. 
Both sets of estimates displayed in Figure 2 show a dramatic rise in the importance of third-party payments for personal health consumption. In 1960, only 2.9 percent of total personal consumption consisted of health care goods and services financed out of employer premium contributions and government insurance payments. In 2007, 15.5 percent of total personal consumption was financed in this way. Employer contributions for health insurance plans and government health insurance payments represent forms of personal income that are excluded from the definition of money income. In 1960, money income would have increased 2.5 percent if these payments for personal health consumption had been included in the definition of income. By 2005, money income would have increased 15.5 percent if these components of income had been included in the money income definition. Note that the longterm rise in health spending and the growing importance of third-party payments for health consumption mean that the standard money income statistics understate the long-term increase in both personal income and consumption as those concepts are defined in the NIPA statistics (Burtless 1996, pp. 272-74). The understatement is much larger for groups in the population that have enjoyed the fastest growth in third-party reimbursement of health care consumption. Since these groups include the aged, poor, and disabled as well as families with breadwinners enrolled in an employer-sponsored health plan, it is apparent that the understatement affects nearly all of the population.

\section{Measuring the Impact of Health Insurance on Consumer Incomes in the MEPS}

The growing importance of health care consumption is clear in the NIPA, which divides personal consumption into broad categories of consumption, one of which is consumption of medical goods and services, including health insurance. On the income side of the NIPA, personal income is defined to include government transfer payments, including those for personal health consumption, and employer supplements to wages and salaries, including contributions to employee health plans. The NIPA definition of personal income thus includes all government and employer spending that pays for personal consumption of health care and health insurance administration. In the aggregate, rising government, employer, and consumer spending on health care is reflected in the income and consumption statistics. It is not, however, reflected in most income statistics that measure the distribution of income across households or trends at different points in the income distribution, including median income. Most publicly available statistics on the distribution of income are derived from an annual supplement to the 
Census Bureau's Current Population Survey (CPS) program. Although the Census Bureau has developed alternative income definitions from time to time, its best known estimates of income are based on the concept of gross money income, that is, pre-tax cash income. This income definition does not include any estimate of the value of insurance provided to workers enrolled in employer- or government-sponsored health plans.

An ideal measure of the impact of health insurance on individual well-being would estimate the market value of the insurance that is provided to individual consumers or to household members who are covered by an insurance policy. It would then subtract from this market valuation the premium contribution that each consumer must pay in order to obtain insurance. In 2008, for example, the average cost of insuring a single worker under an employer-sponsored health insurance plan for one year was \$4,704. On average, workers’ premium contributions paid for 16 percent of the cost of the plan, and employers paid for the rest. Family coverage required total annual premiums averaging $\$ 12,680$. Workers paid average premiums that covered 27 percent of this annual charge. ${ }^{4}$ Aged and disabled Americans who are enrolled in medicare usually pay monthly premiums for coverage, and these premiums should be subtracted from the market value of medicare coverage to determine the value of medicare to enrollees.

The introduction of the MEPS in 1996 has greatly improved our ability to measure the precise impact of health benefits on the distribution of personal income. Like the March CPS, the MEPS household survey provides information on cash income and its components for a nationally representative sample of the noninstitutionalized population. In addition the MEPS obtains unusually comprehensive information on health care utilization, spending on health care and insurance, and sources of payment for personal health care goods and services for people enrolled in the household survey. The MEPS research program has three basic components, a survey of representative households, a survey of the medical providers who supply services to these households, and a national survey of public and private employers to gather information on the types and cost of employee health insurance offered. ${ }^{5}$ For purposes of estimating the distribution of health care consumption and payments in the noninstitutionalized population, the

4 These estimates are based on results from an annual survey of employers sponsored by the Kaiser Family Foundation rather than the MEPS (see Claxton et al. 2008).

5 For a more detailed description of the MEPS program and its component surveys, see the introductory material in Bernard and Banthin (2007). 
first two surveys are the most important components of the project. They provide detailed information on utilization of health care providers, its cost, and the sources of payment for the care received by people in the household sample. Because the reports of household respondents are cross-checked against the responses of providers, the MEPS provides much more accurate information about the cost and sources of payment for medical services than would be possible in a survey aimed solely at households.

The MEPS household survey collects information from a given sample (or panel) of families in five separate surveys that cover overlapping time periods over two calendar years. The analysis reported here is based on income, medical care, and health spending reports of the MEPS panels covering calendar years 1996-2005. This gives us information on incomes, health spending, and insurance reimbursement for a total of 205,000 person years, or slightly more than 20,000 observations per year. Most of our analysis focuses on the incomes and health spending of the sample members who were present in families at the end of December in each calendar year. This sample restriction is intended to make the sample comparable to the one in the Census Bureau's March CPS survey, which enrolls a sample of people at selected addresses at a particular point in time. Census interviewers ask March CPS respondents about household composition at the time of the interview and about personal income and labor force experience in the previous calendar year. Since MEPS households are included in the sample for a period of two years, it is possible that some household members who were present before or after December in a particular calendar year will be absent from the household in December. We exclude the incomes and health care spending of these absent family members from our analysis.

Although the MEPS household survey provides extensive information on the types of providers who supply medical care to people in the sample, our focus is on the total cost of care received, the portion of costs that are directly paid by the person receiving care or by other family members, and the cost of health insurance premiums. The MEPS household survey files permit us measure the total cost of care received by individual household members and also to determine the fraction of this cost that is paid by the household and by individual third-party payers - medicare, medicaid, private insurance, workers' compensation, and so on. Although total health expenditures and medical out-of-pocket payments are separately observed for every household member, it is more difficult to allocate premium payments across individual members, except when the insured family unit consists of just one person. Many employers provide less 
generous premium subsidies to an employee's dependents than they do to the employee. This means the net cost to the family of obtaining insurance for the employee is cheaper than the net cost of insuring each of the employee's dependents. Our calculations assume, however, that the household's out-of-pocket premium payments represent an equal expense for every household member who is covered by the insurance plan.

The MEPS data have some important limitations for assessing the market value of insurance plans covering the survey respondents. Although the MEPS collects extensive cost data from employers, none of these cost data are linked to individual health consumers or to households in the MEPS household survey. As a result, we do not know the cost to employers of paying health insurance premiums in behalf of respondents in the MEPS household sample. As noted above, the MEPS household data file includes information on payments from employersponsored insurance plans to reimburse providers and households for the cost of medical care. It does not, however, contain any information about employers' costs of managing their health insurance plans or paying for third parties to manage their health plans. Thus, an important component of respondents' health consumption - their consumption of health insurance administrative services - is missing from our files although it is counted as part of medical consumption in the NIPA. In addition, the MEPS household survey has incomplete information on respondents' insurance premium payments. For calendar years 1996-2000 respondents were not asked to report employees' premium payments for their employment-based insurance coverage. Starting in 2001, these premium amounts began to be reported to interviewers. For all 10 years in our analysis period, the MEPS household survey fails to include any information about premium payments for medicare. We imputed medicare Part B premiums to respondents in every month when they said they were enrolled in medicare but were not simultaneously enrolled in medicaid. ${ }^{6}$

${ }^{6}$ Medicare premium amounts for 1996 through 2005 are reported in O'Sullivan (2004, p. 5). State medicaid programs pay for the medicare Part B premiums of medicare enrollees who are also enrolled in medicaid. Our imputation procedure will result in some errors. A small percentage of medicare enrollees must pay a premium for Part A benefits, because they did not become eligible for medicare Part A as a result of their own or a spouse's employment in medicare-covered jobs. We understate the premium payments of these enrollees. A larger number of medicare enrollees are enrolled in Part A of medicare but decline to enroll in medicare Part B, either because they have other insurance coverage or because the Part B premium seems too high. Finally, some low-income people enrolled in medicare Part B are entitled to pay less than the standard Part B premium even though they are not enrolled in the medicaid program. Our imputation procedure will overstate the Part B medicare premiums of the last two categories of enrollees. 
The MEPS household survey data can be used to measure well-being, including health consumption, in a way that focuses on each person's or each household's utilization of health care resources. The data in the household survey file permit us to observe the total health consumption received by each member of the MEPS sample. We then subtract from this consumption the money payments made by the family in order to obtain the consumption. The net increment to personal income from health insurance, $\delta_{Y}$, is

$$
\delta_{Y}=H-M-P,
$$

where $H=$ Total health consumption;

$M$ = Out-of-pocket spending for health consumption; and

$P=$ Consumer premium payments for health insurance.

The excess of a person's total health expenditures (including the part reimbursed by insurers) over the out-of-pocket payments made by the consumer for health care and insurance premiums represents a claim on resources in addition to the claim reflected by the person's money income. Many consumers who are covered by health insurance receive little or no health care during the year, of course. These consumers may pay more for insurance than the amount of care that is reimbursed by their insurance plan. The net claim on health care resources can be summed across all household members and added to total household income. It can also be estimated at the individual level and treated as an income component that differs from one household member to another.

Many social scientists are uneasy with an income definition that treats actual health care consumption in excess of out-of-pocket medical payments as an addition to income. People who consume more-than-average health care services ordinarily do so because they are sick or injured. Those who consume the most costly services are the sickest and most seriously impaired. It is hard to argue that a person who receives third-party payments covering $\$ 100,000$ of medical care is $\$ 100,000$ better off than a person enrolled in the same insurance plan who is so healthy he or she never sees a doctor or the inside of a hospital. While this observation is correct, it simply means that we cannot use estimates of actual resource utilization to make interpersonal comparisons of well-being between two particular individuals. We can, however, use our proposed measures to compare resource utilization for different age groups at the same point in time or at different points in time. In particular, we can determine whether standard 
measures of money income understate or overstate the relative income position of different population groups.

\section{The Distribution of Benefits Derived from Health Insurance: Impacts of Health Status, Income, and Age}

Health outlays differ considerably from one person to the next. In a society with broad health insurance coverage, the main reason for spending differences is the disparity in health statuses across individuals. The distribution of health spending across the population is much more unequal than the distribution of income. Tabulations of the 2004 MEPS household survey show that the bottom 50 percent of health consumers accounted for just 3.1 percent of total health care expenditures. In contrast, the top 1 percent of spenders accounted for 22.5 percent of spending, and the top 15 percent of consumers accounted for almost three-quarters of total spending (Kaiser Family Foundation 2007, p. 5). This concentration of health care expenditures is much more pronounced than the concentration of income. Not surprisingly, people who are in poor health receive an outsize share of personal health spending in a given year. The state of a person's health is more important than family income in determining the total cost of care a person receives.

Figure 3 shows the relationship between individual health care spending, on the one hand, and income and reported health status, on the other. The calculations are based on 10 years of data in the MEPS household survey. MEPS respondents were asked to assess the health status of every household member on a five-point scale ("Excellent," "Very good," "Good," "Fair," and "Poor"). They were also asked about their family's gross money income. We used the annual income data to classify every person in the MEPS sample into five equal-size income classes. To make this classification we first computed the household-size-adjusted annual income of each household and person in the sample. Because larger households need more money than smaller households to enjoy the same standard of living, it is useful to adjust households' reported incomes to reflect this fact. A common adjustment, which we use here, is to assume that household spending needs go up in proportion to the square root of the number of household members. Formally, size-adjusted (or "equivalent") income ( $\hat{I}$ ) is equal to unadjusted household income ( I ) divided by household size (S) raised to an exponential value (e), that is, $\hat{\mathrm{I}}=\mathrm{I} / \mathrm{S}^{e}$. Our assumption implies that the value of $e$ is $1 / 2$. For purposes of this 
calculation, we also assume that household members share income equally, implying that every person in the household has an identical income.

The results in Figure 3 show average health spending amounts for people in cells defined by respondents' reported health status and position in the income distribution. ${ }^{7}$ To keep the chart simple we only show results for three of the five income groups, the bottom, middle, and top fifths of the distribution. Among people who report the same health status, income has a fairly consistent effect on total health care consumption: People with higher incomes tend to consume more health care. However, the impact of income on health consumption appears small in relation to the impact of respondents' health status. Holding constant health status, a person in the middle fifth of the income distribution receives medical care that costs roughly 15 percent more than the care received by a person in the bottom fifth. A person in the top fifth of the income distribution receives care that costs about one-third more than a person in the bottom fifth. These are sizeable spending differences to be sure, but they are dwarfed by the spending differences between people who are in poor and excellent health. A person in the bottom fifth of the income distribution who is in poor health receives care that costs more than seven times as much as the care received by a person in the top fifth of income who is in excellent health.

Health care consumption increases with age, and a principal reason is that poor health becomes more common as adults grow older. Figure 4 shows the percentage of respondents with poor health in four broad age groups. The results are separately tabulated for people with different ranks in the income distribution. Once again, the tabulations reflect average responses for 10 calendar years of the MEPS household survey. In each age group poor health is more common among people with lower household incomes. Many adults with below-average income may in fact be needy as a result of their health. Poor health may prevent them from working in a full-time job or in any job at all. Within each income category poor health is much more common at older ages. Among adults in the middle income category, 18 percent of respondents age 65 and older report being in poor health in comparison with less than 5 percent of respondents between 18 and 44. The spending totals shown in Figure 3 show why the

7 The estimates were obtained by averaging the results from ten separate regressions, one each for the ten calendar years included in the analysis. To convert spending amounts into constant 2005 prices each year's estimate was deflated using the personal consumption expenditure deflator for medical care. 
differences in the prevalence of poor health will have pronounced effects on health expenditures across age groups.

Even holding constant respondents' health status and position in the income distribution, the distribution of annual health consumption is highly skewed. Figure 5 shows selected results from quantile regressions predicting annual health care expenditures in the 2001-2005 MEPS household surveys. The regressions are performed with health spending amounts that have been converted to constant 2005 prices using the personal consumption expenditure deflator for medical care. The results displayed in Figure 5 focus on MEPS respondents with annual sizeadjusted incomes in the middle one-fifth of the income distribution. ${ }^{8}$ To simplify the chart we have only plotted regression coefficients for three of the five health statuses; the results for "very good" and "fair" health are not shown. For each of the health statuses displayed, the figure plots the 20 distinct quantile regression estimates from $\tau=0.05$ to $\tau=0.98$. For respondents within each health status group, health spending is highly concentrated. Respondents in the bottom 10 percent of the expenditure distribution consume little health care regardless of their reported health status. Among respondents in excellent health, about three-quarters are predicted to consume less that $\$ 1,000$ in health care per year. In contrast, among respondents who describe their health as poor, three-quarters will consume more than $\$ 2,600$ in medical goods and services in a year.

A well-functioning insurance system should protect consumers against very large personal outlays on medical care, no matter what their health status. The U.S. insurance system offers excellent protection to many people, moderate protection to some, and little or no protection to others. The top panel in Figure 6 shows out-of-pocket outlays on health care consumption for the same three groups of MEPS respondents considered in Figure 5. All respondents had incomes in the middle one-fifth of the income distribution and were in excellent, good, or poor health. For each health status the chart displays quantile regression results showing the distribution of out-of-pocket outlays for medical goods and services, excluding health insurance premiums. ${ }^{9}$ The results suggest that 30 percent of middle-income respondents

${ }^{8}$ The full set of regressions is run using all person-year observations from the 2001-2005 MEPS household survey. The independent variables in the regressions include a full set of interactions between the health status indicator and the person's position in the income distribution.

${ }^{9}$ Consumer outlays for medical goods and services and health insurance premiums are converted into constant 2005 dollars using the CPI-U-RS deflator 
who are in poor health spend at least $\$ 2,000$ a year on their health care. Only 8 percent of respondents who are in good health and about 2 percent of respondents in excellent health spend that much in a year. About 5 percent of respondents in poor health spend at least $\$ 6,000$ a year on care.

Most Americans must pay premiums for their insurance coverage. Starting in 2001 the MEPS household survey asked about health insurance premiums paid by respondents for their employer-sponsored insurance. (In earlier years MEPS interviewers only asked about premium payments for private insurance not provided by employers.) The data on private insurance premium payments plus our imputations of medicare insurance premiums allow us to estimate the total insurance premiums paid in behalf of each MEPS household member who is covered by private insurance or medicare. The bottom panel in Figure 6 shows quantile regression estimates of the distribution of these premium payments for 2001-2005 MEPS respondents in the middle income group who were in excellent, good, or poor health. About one-quarter of the respondents in poor health and one-third of the respondents in good or excellent health do not report any spending for health insurance. Some of these people are uninsured, while others receive free insurance from medicaid or an employer. On average people in poor health report paying higher insurance premiums than people who are in good or excellent health. The premium differences are, however, much smaller than the spending differences for medical goods and services.

People covered by health insurance typically pay far less for premiums than the expected value of the insurance protection they receive. Medicaid enrollees pay no premiums at all, and people insured by medicare pay premiums that cover only a little more than a tenth of program costs. Workers and retirees enrolled in employer-sponsored insurance typically receive large subsidies from their employers for coverage. In a given year, however, some insured workers receive reimbursement for very large health costs while others pay higher premiums than they receive back as reimbursement for their health care consumption. Figure 7 shows the distribution of annual gains and losses from insurance for middle-income MEPS respondents who were in excellent, good, or poor health in 2001-2005. Once again, the distributions are estimated using quantile regression. The dependent variable in the regression is the difference between insurance reimbursement payments received in a year and the person's premium costs 
for insurance. ${ }^{10}$ The top panel of Figure 7 shows the pattern of net insurance gains and losses in the bottom half of the distribution. Note that about 15 percent of middle-income respondents in poor health and 35 percent of people in good health are predicted to make larger annual premium payments than they receive in health insurance reimbursement. The value of health insurance for most people is revealed in the bottom panel of Figure 7. It plots the distribution of gains from insurance for people in each health category who derive the biggest net gains under their insurance plans. About one-fifth of middle-income people who have poor health can expect to derive net benefits that will be $\$ 20,000$ a year or more. For respondents who report good or excellent health, the percentage obtaining large net gains from insurance is far smaller. Among middle-income individuals who are in excellent health, for example, less than 5 percent can expect to receive net benefits that exceed $\$ 3,500$ a year.

Aggregate health care spending has risen faster than total consumption and total household income. This trend has important consequences for groups in the population that are heavy users of the health care system. Since the elderly are major consumers of care, they have been disproportionately affected by the long-term trend toward higher prices and more intense utilization of medical goods and services. Figure 8 shows the age distribution of total health consumption when total health care consumption is measured as a percent of the age group's aggregate money income. The calculations are performed using MEPS household survey data that are tabulated at the individual level. To calculate each person's gross money income, the household's total money income is simply divided equally among all household members. The survey files show consumption of health care goods and services on an individual basis. Thus, the estimates shown in the chart reflect each age group's health consumption measured as a percent of the age group's pro rata share of household money income. The figure shows that health consumption represents a monotonically rising share of income as adults grow older. Among people who are between 75 and 79, the consumption share is 4.2 times larger than it is for people between 35 and 39; it is 1.7 times larger than for people between 65 and 69 .

10 The dependent variable is calculated by subtracting the person's out-of-pocket spending on medical care and health insurance premiums from his or her total consumption of health care. In some cases this approximation slightly overstates the net gain or loss from health insurance, because it includes some health consumption that is received as charity care from providers. On the other hand, because our estimate of health consumption excludes nearly all of the administrative cost of managing the health insurance system, it seriously understates the total subsidy that the insured population receives from insurance. 
Figure 8 also shows how the income share represented by health consumption has increased over time. The bars indicate the average income shares in the five years between 1996 and 2000, while the line indicates the shares in 2001-2005. Note that the income share increased in every age group between the two periods. For MEPS respondents in all age groups, health consumption (excluding premium payments for insurance) represented 10.0 percent of gross income in the earlier period and 12.6 percent of income in the second. Both these estimates are substantially lower than the health consumption share implied by aggregate totals reflected in the NIPA and NHEA. There are a number of reasons for the large discrepancy. Estimates based on the NIPA and NHEA include the administrative costs of the health insurance system, and these are largely excluded from the MEPS household survey responses. In addition, the NIPA and NHEA estimates include the health consumption of the institutionalized population, while the MEPS household survey is restricted to the noninstitutionalized population. Since many of the institutionalized are in nursing homes or other long-term care facilities, their average health care consumption is likely to be much higher than the average consumption observed in the MEPS sample. Finally, the MEPS household survey misses some of the health care spending of the sample that is enrolled (see Sing et al. 2006). Even so, both the MEPS survey responses and the NIPA and NHEA statistics show a considerable rise in health spending relative to household income over the 1996-2005 period.

Part of the health spending reported in the MEPS interview is financed out of household budgets and part is financed through health insurance reimbursement payments that are larger than household premium payments to insurers. The MEPS interviews do not provide complete information about household premium payments between 1996 and 2000, but they do give information covering 2001-2005. These data can be used to calculate the share of 2001-2005 health care consumption that was financed with out-of-pocket household spending on health services and insurance premiums. Figure 9 shows the results of these calculations by age group. Like the tabulations in Figure 8, the results in Figure 9 show health outlays measured as a percent of gross money income. The lower, dark part of each bar indicates the amount of spending that is financed out of household budgets, either as out-of-pocket payments to providers or as health insurance premiums. These payments absorb a rising percentage of money income as adults grow older. People who are between 75 and 79 devote approximately three times the proportion of their household budgets to medical care and insurance premiums as do 25-to-29 
year-olds. The lighter portion of each bar shows the net reimbursement payments from insurance that each age group receives, measured as a percentage of the group's gross money income. Net reimbursement payments, which are not included in the Census Bureau's definition of money income, are much larger for older age groups than for the young. If the net reimbursement payments were counted in income, the gross income of 25-to-29 year-olds would rise 3.6 percent and the income of 75-to-79 year-olds would increase almost 27 percent.

The gains in income would be proportionately larger for people near the bottom of the income distribution. Consumption of health care goods and services is relatively equal across the income distribution. Moreover, Americans who have low incomes receive third-party reimbursement for a larger percentage of their consumption. Figure 10 shows average health care consumption, excluding premium payments for health insurance, across the income distribution. The top panel of the chart shows consumption levels in the population under age 65 , while the bottom panel shows consumption among the elderly. Individuals in each age group are divided into fifths of the household-size-adjusted income distribution, and average spending amounts are calculated within each fifth of the distribution for the 1996-2000 and 2001-2005 periods. Among those under 65, health consumption is modestly higher in the top income group than it is in the bottom four-fifths of the distribution. On the other hand, consumption is slightly higher at the bottom of the distribution than it is in the middle of the distribution. In the elderly population health consumption tends to fall in higher ranks of the income distribution. In both periods covered by the chart, health consumption is noticeably higher in the bottom fifth of the income distribution compared with the middle or top of the distribution. These spending patterns are the result of broad insurance coverage in the population, which protects most of the poor and seriously ill from paying for the full cost of the care they receive. The affluent can afford to pay for more expensive care, and many of them are covered by excellent health insurance. However, compared with people who have low incomes the affluent are less likely to suffer from poor health.

For the 2001-2005 period we can calculate the cost to households of paying for health consumption and insurance premiums. These costs are displayed in Figure 11. As in Figure 9 we show health spending measured as a percent of gross money income. The lower, dark part of each bar indicates the amount of health consumption that is financed out of household budgets, either as out-of-pocket payments to providers or premium payments to health insurers. The 
lighter part of each bar shows the net reimbursement payments from insurance that each income group receives, measured as a percentage of the group's gross money income. The top panel in the chart shows estimates for the nonaged population, and the bottom panel displays estimates for the elderly. Note that the relative burden of paying for health care and insurance premiums is greater for people in lower ranks of the income distribution than for the well-to-do, and it is greater for the aged than the nonaged. People under 65 who are in the bottom one-tenth of the income distribution devote 18 percent of their household budgets to medical care and insurance premiums, whereas the nonaged who are in the middle of the income distribution spend only 5 or 6 percent of their gross incomes on these items. The aged population devotes a much larger fraction of its household budget to health care and insurance expenses. On the other hand, both the poor and the aged receive supplements to their money incomes as a result of net reimbursement payments from insurers. These reimbursement payments, which are excluded from the definition of gross money income, are proportionately more important for the poor and the elderly than they are for the rich and the nonelderly. If the net reimbursement payments were added to gross money income they would boost incomes in the bottom tenth of the income distribution by 65 percent in the nonelderly population and by 130 percent in the aged population. In the middle of the distribution, the net value of the reimbursement payments would add about 6 percent to the gross incomes of the nonelderly and 25 percent to the incomes of the elderly.

If Americans' net gains from health insurance were treated as equivalent to an increase in their gross money income, the apparent improvement in average income would be bigger for the elderly than for the young. Figure 12 shows the age distribution of these income gains in the five years between 2001 and 2005. The top panel in the chart displays the age distribution of household-size-adjusted (or equivalent) annual income under two definitions. Under the first definition we simply calculate the size-adjusted household income of every person in the population using the Census Bureau's concept of gross money income. Under our second income definition we add the household's net gain from health insurance to its gross money income to derive total household income. Our size adjustment procedure under both definitions assumes that income is shared equally among every person in the household. Thus, if the household contains both a 28-year-old and a 77-year-old, the net insurance gains of each person are added to the household's gross money income before the household size adjustment is 
performed. Not surprisingly, the inclusion of net insurance gains in the definition of household income improves the relative position of households containing an older person. Under the more expansive definition of income the average equivalent income of 75-79 yearolds is increased by $\$ 6,340$ (or 23 percent) whereas the average equivalent income of 25-29 yearolds is only raised by $\$ 1,750$ (or 5 percent).

As noted above, the net income gains from insurance are highly variable across the population. This is revealed in the bottom panel of Figure 12, which compares the average and median gain from insurance in each age group. Unlike the estimates in the top panel, these estimates are not adjusted for household size. The estimates of net gain from insurance are calculated at the individual level. For each person in the MEPS household survey we calculated the difference between insurance reimbursement payments for care received by the individual and insurance premium payments made by the household in behalf of the individual. For individuals in each age group, the median gain from insurance is considerably lower than the average gain. For many younger age groups, the median gain is $\$ 0$ or not far above $\$ 0$. This implies that the median person has no insurance and no medical care costs or has received reimbursement payments that are very close to the annual premium payment. As indicated in the top panel of Figure 7, there are many people who pay more in insurance premiums than they received back in insurance reimbursement payments, but in no age group does this represent the situation of the median respondent.

The large difference between the median and average net gain from insurance, especially among older adults, shows why it is so hard to assess the value of health insurance for most Americans. Relatively few people purchase unsubsidized insurance in the open market, and those who do are differentially selected on the basis of poor health or strong risk aversion. The value of insurance differs widely depending on the underlying health status of the insured person. People who are in poor health derive much greater benefits from comprehensive insurance than people who are in good or excellent health. In addition, the value of a particular plan depends on features of the plan that are rarely ascertained in household interviews and may be unknown to survey respondents. These features include deductibles, copayments, coinsurance rates, exclusions, and coverage limits. In the MEPS household survey we observe the actual pattern of insurance reimbursements across health care consumers, but it is difficult to predict what reimbursements a healthy individual would receive if he or she experienced serious illness 
or a five-day stay in a hospital. Nonetheless, Figures 9, 11, and 12 offer compelling evidence on the age distribution of net benefits Americans receive under the health insurance system. These imply that a substantial amount of income is excluded from standard measures of household income and that the amount excluded is much greater in the aged population than it is for the nonelderly.

\section{Replacement Rates that Reflect Health Insurance}

The pension replacement rate indicates the percentage of a worker's earnings lost at retirement that is replaced by a pension. The Social Security Administration estimates, for example, that a worker earning the median lifetime wage who reached age 65 and retired in 2008 would be entitled to a pension that replaced about 43 percent of his or her average lifetime wage (Clingman et al. 2008, p. 4). We can obtain broader estimates of the replacement rate by calculating the percentage of lost wages that is replaced by occupational pensions and meanstested assistance benefits as well as social security pensions. These estimates focus on the replacement of money wages that are lost as a result of retirement. A more comprehensive estimate of the replacement rate would also account for the acquisition or loss of health insurance that occurs after retirement. Nearly all workers become entitled to medicare when they reach age 65, and workers who receive Disability Insurance benefits become eligible for medicare two years after the onset of their disability. Many indigent retirees qualify for medicaid as well as medicare. Whether these kinds of insurance are more or less generous than the insurance policies that cover active workers depends on the availability and generosity of employer-sponsored insurance.

The MEPS household survey provides data that shed light on the generosity of health insurance before and after retirement. These data can be used to calculate a replacement rate that includes the value of health insurance. We use synthetic cohort analysis to obtain an estimate of the gain or loss of income that occurs as a cohort withdraws from the work force. Under our narrowest definition of income, we only track the cash income that is derived directly from work, either as money wages or as net self-employment income. Under a broader income definition, we also include all other sources of household income, including public and private pensions, transfer payments, and capital income flows that are reported to MEPS interviewers. Our most comprehensive income definition adds to gross money income the net gains that households derive from insurance reimbursement. For a particular household, the net gain is the household's 
insurance reimbursement payments for medical care minus its insurance premium payments. Our goal is to estimate the rate at which income declines over retirement using data on earnings, gross money income, and net health insurance reimbursements in the 2001-2005 MEPS interviews.

We can use information about changes in the average income of a given cohort between two points in time to infer how fast income falls between two ages. Results from successive birth cohorts can then be combined to make inferences about how fast income falls over a longer span of ages. For example, combining information from the 2001 and 2002 MEPS household surveys we can easily calculate the rate of change in income received by people who were 50 years old in 2001 and 51 years old in 2002. ${ }^{11}$ For this particular birth cohort, it is straightforward to measure income at the older age as a proportion of income at the younger age, say $r_{51}=$ $Y_{51} / Y_{50}$. Using estimates of $r$ from successive birth year cohorts, aged 51 through 71 in the 2002 survey, we can form estimates of income at a later age, say, $A$, as a proportion of a cohort's income at age 50:

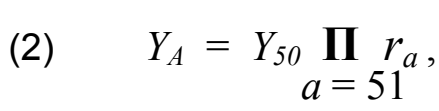

Figure 13 uses the procedure just described and data from the 2001-2005 MEPS household surveys to calculate the rate of decline in real incomes between ages 51 and 71 . In order to reduce the sampling variability of the estimates, we estimated the changes in income that occurred over a two-year period for birth cohorts that were defined to span two birth years. For example, we calculated the income changes that occurred between 2001 and 2003 for people who were 50 or 51 in the earlier year and 52 or 53 in the later year. The estimates shown in the chart average together the estimates for three pairs of years, 2001 and 2003, 2002 and 2004, and 2003 and 2005. All of the calculations are performed using household-size-adjusted income

11 In the example just given, it would be possible using MEPS data to calculate actual income changes for individual households. Since households are interviewed over a two-year period, half the 2002 MEPS sample consists of households that were also in the sample in 2001. However, the resulting samples of persons near retirement age are quite small. To calculate replacement rates we therefore used the synthetic cohort analysis method described in the text. 
amounts. $^{12}$ Before calculating the rate of change in incomes between two years, we converted all income amounts into constant dollars using the CPI-U-RS price deflator.

The chart shows a clear pattern of decline in household-size-adjusted incomes as MEPS respondents grow older. The fastest rate of decline occurs under the income definition that only includes a household's labor earnings. As MEPS respondents rise in age from 50-51 to 70-71, our estimates imply that labor earnings will fall 70 percent. The rate of income decline under the other two definitions is much smaller. During the same 20-year span, gross money income is estimated to fall about 30 percent and gross money income plus the net income gain from health insurance is predicted to fall only 14 percent.

Three main factors account for the relatively small decline in household-size-adjusted income in the face of a sharp fall in labor earnings. First, increases in social security benefits and employer pensions offset a sizeable percentage of lost labor income. Between ages 50-51 and 60-61, for example, the estimated increase in social security and occupational pensions offsets about 38 percent of the decline in earnings. Between 60-61 and 66-67, the increase in these income sources offsets about 85 percent of the drop in earnings. Second, older households tend to grow smaller as household heads grow older. Between ages 50-51 and 70-71, average household size falls about 30 percent. In some cases a spouse dies, and in other cases a household member chooses to move out. Both kinds of change in family composition reduce the number of household members who must be supported out of household income. Finally, aged adults tend to receive bigger net transfers from the health insurance system as they grow older. This factor alone tends to offset about 20 percent of the drop in gross earnings that occurs between ages 50-51 and 66-67. The contribution of generous health insurance becomes even more important at older ages because of the steep rise in subsidized health consumption that occurs at older ages. As shown in the bottom panel of Figure 12, people who are past age of 50 obtain net transfers from the health insurance system that are many times greater than the net transfers received by people in their 20 s and 30s. An important reason is that nearly everyone

${ }^{12}$ The total sample used in the estimation consists of 20,596 MEPS respondents who were between ages 50 and 71 in the 2001-2005 household surveys. To maximize our sample size, the calculations are performed with a sample consisting of both men and women. For a married-couple family, this may mean that both the husband and the wife will be separately included in the tabulations, although the income information for each spouse might be used to calculate the income change occurring at different ages. 
over 65 is eligible for generously subsidized public health insurance. Another is that poor health and big medical bills are much more common among the elderly than among the nonelderly.

The estimates displayed in Figure 13 can be used to make simple approximations of the replacement rate. What percentage of lost labor earnings are replaced through increases in other sources of income? The percentage of earnings replaced varies by age. The earnings loss that households experience when a household member is between 50 and 61 is not replaced as generously as the earnings loss that occurs after age 61. It is convenient to divide estimates of the replacement rate into separate estimates for earnings losses that occur between ages 50-51 and 60-61, between ages 60-61 and 66-67, and between ages 66-67 and 70-71. Using information about changes in gross money income, it appears that increases in other sources of cash income offset 38 percent of the earnings loss that occurs between 50-51 and 60-61. The replacement rate rises to 81 percent for earnings losses that occur between 60-61 and 66-67, and it then falls to 14 percent for earnings losses that occur between 66-67 and 70-71. When replacement rate estimates are based on estimated changes in households' money incomes and net insurance gains, the estimated replacement rate rises. In the three age ranges just mentioned, the most comprehensive estimate of the replacement rate implies that 56 percent, 99 percent, and 68 percent of earnings losses, respectively, are replaced. These estimates indicate that the increased value of health insurance protection as a cohort ages is an important source of income protection for the retired elderly.

\section{Effects of Employer Insurance Contributions and Government Health Benefits at the Household Level: Census Bureau Estimates}

The Census Bureau has developed estimates of household income that include a prediction of the value of health insurance available to households (U.S. Bureau of the Census 1993; Cleveland 2005). In one of its current income definitions, for example, the Bureau includes estimates of the value of employer contributions to employee health plans for workers who say they were covered by an employer plan. Predicted employer contributions are imputed to each worker in the March CPS based on model estimates developed using data from a separate survey of employers. In that survey employers were asked about the contributions they made to plans covering their workers. In another income definition the Bureau includes estimates of the "fungible insurance value" of medicare and medicaid for people in the CPS who say they were 
insured by medicare or medicaid for part or all of the previous year. The Bureau estimates the insurance values of medicare and medicaid by calculating the average medicare and medicaid outlay per enrollee, by risk class, separately in each of the 50 states. In its income estimates for 1992 the Bureau defined two risk classes for medicare (older than age 65 and disabled) and four risk classes for medicaid (older than 65, younger than 65 and disabled, age 21-64 and not disabled, and age 0-20 and not disabled).

The Census Bureau developed its alternative income definitions in part to estimate poverty rates under more comprehensive measures of family resources. The Bureau did not believe it could include 100 percent of the medicare and medicaid insurance valuation for respondents with low cash incomes. This explains its decision to count only the "fungible" value of insurance in its alternative measure of income. The fungible value of health insurance is zero in the case of families who do not have enough cash and near-cash resources to pay for their minimum food and shelter costs. As cash and near-cash resources rise above this threshold an increasing percentage of the insurance value of medicare and medicaid is counted as fungible and included in family income. The full insurance amount is included in income when a family's cash and near-cash resources are greater than the difference between family resources and the minimum resource threshold (U.S. Bureau of the Census 1993, pp. B1-B3).

Even though the full insurance value of medicare and medicaid is not reflected in the Census Bureau's fungible insurance value estimates, its imputations of medicare, medicaid, and employer health insurance contributions added an average of 9.3 percent to the household-sizeadjusted gross money income reports obtained in the CPS files covering 1996-2005 incomes. The addition to average size-adjusted income has grown over time, especially since the late 1990s. In 1998-1999 the inclusion of employer health insurance contributions and the fungible value of medicare and medicaid in household income added 7.9 percent to average size-adjusted gross money income in the March CPS files. By 2004-2005 the inclusion of these items added 11.7 percent to the average amount of size-adjusted money income. Thus, the Census Bureau estimates of insurance value, like our estimates based on the MEPS data, show a strong upward trend in the economic value of health benefits.

Of crucial importance is how these insurance benefits are distributed across age groups. The Census Bureau treats employer insurance contributions as an addition to wage income, and it imputes the income to the employee or retiree who is covered under the employer plan. 
However, other family members also derive benefits from the employer's contributions, so part of the benefits from the employer contribution should also be attributed to family members covered by the plan. The Census Bureau's estimates of employer contributions for group health plans do not allow us to identify which household member derives benefits from the extra health consumption that the insurance contributions allow. In a family where more than one member is covered by the employer's plan it is unlikely benefits are concentrated solely on the wage earner whose employment gives rise to the family's insurance coverage. If the benefits are spread equally across family members, it seems plausible to treat health benefits as equally available to all members of the family. We use the same assumption when adding the fungible insurance value of medicare and medicaid to a household's income. The extra income is available equally to all household members, even though some members may not be covered by the insurance policy.

This is the assumption used in Figure 14 to assess the value of health benefits estimated by the Census Bureau. The Bureau's estimates of the fungible insurance value of medicare and medicaid and employer contributions to employee health plans are treated as an addition to household income. They are assumed to be equally available to all household members, regardless of age, and they are translated into additions to equivalent household income. The two panels of Figure 14 show the distribution of the resulting income gains across the age distribution, with the gains measured as a percentage of the age group's average size-adjusted gross money income. The estimates reflect average values for the 1996-2005 decade. The Bureau's estimates imply that the income additions resulting from the medicaid program are fairly evenly distributed across the age distribution. In contrast, the benefits of the medicare program are concentrated in the aged population, and the income gains attributable to employer subsidies for worker and retiree health plans are concentrated on the working-age population and its dependent children. The bottom panel in Figure 14 shows how the age distribution of health benefits changed between the 1996-2000 and 2001-2005 periods. Note that the estimated additions to income from health insurance coverage are uniformly higher in the later period compared with the first. This is consistent with the findings from the MEPS household survey as well as the time series trends reported in the NIPA and NHEA.

Figure 15 shows the implications of the Census Bureau estimates for the age distribution of relative equivalent personal income. For each income definition, the numbers in the chart 
show the average equivalent income in an age group measured relative to the populationaverage income under the same definition. The bold solid line shows the age distribution of the Bureau's standard income measure, before-tax money income. These estimates suggest that older Americans have the lowest average equivalent incomes of any age group. The peak equivalent lifetime income is attained by Americans between 50 and 54, whose average money income is 35 percent higher than the average for Americans of all ages. Equivalent money income falls off sharply after age 60. People who are between 70 and 74 have average money income that is 20 percent below the population average, about the same income deficit as that of children between ages 0 and 4. Americans older than 74 have the lowest equivalent money incomes in the population. (The lifetime income pattern is similar if we use relative median incomes rather than mean incomes to assess the positions of different age groups.)

The broken line in Figure 15 shows the distribution of equivalent disposable personal incomes. Disposable cash and near-cash income is equal to money income plus near-cash transfers (food stamps and public housing subsidies) minus estimated income and payroll taxes. Not surprisingly, the addition of near-cash transfers and the subtraction of tax payments equalizes the distribution of measured income across age groups. Equivalent incomes at the peak income ages are reduced, while relative incomes at the low-income ages are increased, most notably in the population past age 65. The third line in the chart shows average equivalent incomes when the Census Bureau's estimates of homeowners' return on net home equity are added to households' disposable incomes. ${ }^{13}$ The effect of this addition is to boost the estimated incomes of age groups, such as the elderly and near elderly, that are most likely to live in owneroccupied homes, and especially in homes with small mortgages in relation to their value. Finally, the fourth line shows the age profile of income under a definition that includes both the net return on home equity and the Census Bureau's estimates of the value to households of government insurance and employer contributions for health insurance. The inclusion of these

13 The Bureau imputes an estimate of implicit rental income from owner-occupied homes based on the assumed financial return that homeowners could earn on the net equity they hold in their homes. A household's net home equity is simply the difference between the market value of its home and the balance on its home mortgage. The Bureau assumes that homeowners earn a return on net home equity equal to the municipal bond rate. From this estimate of financial return the Bureau subtracts one of the main costs of ownership, the homeowner's property tax. The surplus of return on net home equity over the property tax liability is counted as income in the Bureau's experimental income measure number 15 (Cleveland 2005). All of the Bureau's imputations of home value, mortgage balances, and property tax liabilities are based on responses in the American Housing Survey. 
items in countable income reduces slightly the estimated relative incomes of young and working-age Americans and significantly increases the relative incomes of the population 65 and older. Among the oldest old, those past age 80, equivalent average income rises from 66 percent of the population average under the Census Bureau's standard money income definition to 93 percent of the population average under the broadest income definition considered. Under this broad income definition, the population between 65 and 74 has equivalent income that is substantially higher than the population-average income. Much of the apparent improvement in the relative income position of the elderly is the result of adding the value of health benefits, mostly medicare, to their disposable cash and near-cash incomes.

\section{Impact of Health Benefits on Disposable Income}

The public-use MEPS files do not contain estimates of public housing subsidies, household payments for income and payroll taxes, or the return homeowners obtain on their net home equity. It is thus not possible to calculate the disposable incomes of MEPS respondents under a comprehensive income definition. One possibility is to develop housing subsidy and home equity imputations and tax calculation programs to predict the missing variables in the MEPS file. Another approach, which we follow here, is to use reports of total health spending, payments from third-party payers, and health insurance premiums in the MEPS file to predict these same variables for families and households in the CPS file. Since the CPS file already contains estimates of housing subsidies, returns on home equity, and tax payments, it is then straightforward to examine the effects of actual health care spending and third-party reimbursement on the net incomes of CPS households.

We have imputed health spending, payments from third-party payers, and health insurance premiums onto CPS households using the responses of similar but randomly selected households in the MEPS. The imputation was done using a statistical matching procedure known as cold decking. Cold decking is ordinarily used to impute values for a missing variable in a file using information from another survey in which the variable was ascertained. For the procedure to work, both survey files must contain one or more variables in common so that a statistical match can be performed. In a standard cold deck imputation, respondents in both survey files are stratified into cells defined by identical categorical variables. Within each cell, a donor (that is, an observation in the survey file with complete information) is randomly selected to represent each observation in the file that is missing the crucial variable. The procedure is 
ordinarily carried out with the proviso that no donor can be selected more than a specified number of times. Once a donor and missing-variable observation are matched, the valid responses of the donor are copied over to the observation with missing information. In the event that a donor is not available in the exact cell in which the target observation is a member, the procedure advances to succeeding higher level cells until a donor is found. In our case, donors are randomly selected from appropriately defined cells in the MEPS file to supply health spending and insurance reimbursement information for households in the CPS file. In performing the imputations, families in the MEPS and CPS were sorted by critical characteristics (or key variables) to ensure that actual health spending and reimbursement amounts from a MEPS family were matched to a similar family on the CPS. Our key variables included health status indicators, the family's insurance coverage under various insurance plans, and detailed family composition indicators, including indicators of the age and marital status of family members. Details of the imputation are described in an appendix.

The statistical match was successful in duplicating in the CPS file the pattern of medical expenditures and insurance reimbursement observed in the MEPS file. The household-sizeadjusted imputations of total medical expenditures in the CPS file have an average value that is within 2.3 percent of the comparable amounts in the MEPS, and the implied average estimate of total health spending minus out-of-pocket payments minus health insurance premiums is within 1 percent of the corresponding amount in the MEPS file.

Because the MEPS imputations are on a file that contains the Census Bureau estimates of medicare and medicaid insurance value and employer contributions to employee health plans, it is possible to directly compare the MEPS imputations with the Census Bureau estimates. Figure 16 shows such a comparison. It shows the relationship between health spending amounts and Census Bureau estimates of insurance value and employer contributions at successive points in the distributions of size-adjusted disposable income, including homeowner returns on net home equity. The tabulations are based on CPS data for calendar years 2001-2005, including our imputations of health spending and insurance reimbursement derived from the 2001-2005 MEPS household file. The Census Bureau estimates of insurance value are displayed as a bold dark line in the chart. The top line shows estimated total health care expenditures based on the MEPS imputations at successive points in the income distribution. The pattern is very similar to the actual spending patterns observed in the MEPS. As in the MEPS file, the health spending 
imputations in the CPS file show little systematic relationship between a person's size-adjusted 
income and total health expenditures. The next lower line shows health expenditures net of the out-of-pocket payments that families make in order to obtain care. Since out-of-pocket spending rises modestly with income, this line has a slight negative slope.

The bottom line in Figure 16 shows health spending minus both out-of-pocket payments for care and family spending on health insurance premiums. This line shows a more pronounced downward slope, reflecting the fact that higher income families tend to spend larger amounts on insurance premiums. The lower line reflects the net amount that should be added to household disposable incomes to capture the consumption households enjoy that is not purchased out of the household's after-tax cash and near-cash income. ${ }^{14}$ Since this line lies below the Census Bureau estimates of insurance value, there is a smaller addition to disposable income than implied by the Bureau's estimates, with the biggest difference between the two sets of estimates at the top on the disposable income distribution.

The Census Bureau estimates of insurance value are greater than the MEPS estimates of the net gain from health insurance for a couple of reasons. There are a number of reasons for the discrepancy. First, in the MEPS imputations households' premium payments for medicare and private insurance are subtracted in calculating the net gain households derive from insurance. The Census Bureau does not subtract medicare insurance premiums. Second, part of the administrative cost of the insurance system is reflected in the Census Bureau's estimates of insurance value. A substantial percentage of employers' health insurance premiums pay for the administration of the health insurance system. As noted above, the health spending amounts recorded in the MEPS household survey primarily reflect the cost of medical goods and services consumed by household members. Very little of the administrative cost of insurance system is reflected in these spending amounts. ${ }^{15}$ Finally, because the Census Bureau imputations of medicare and medicaid are based on administrative data supplied by public insurance agencies and the Bureau's imputations of employer contributions, which are based on employer surveys, it

14 The consumption is purchased with government funds or employer contributions to employee health plans. Most labor economists believe that workers indirectly pay for the employer contributions through lower wages.

${ }^{15}$ None of the administrative cost of medicaid and very little of the administrative cost of medicare or employer-sponsored group health insurance will be reflected in the MEPS spending estimates. The only health administration costs that are fully reflected in the MEPS household file are those for unsubsidized private health insurance, because these administration costs are fully reflected in the nongroup insurance premiums that households must pay. 
is likely that a higher percentage of total insurance reimbursement is actually reflected in the 
Census Bureau imputations. On the other hand, the Bureau's imputations of medicare and 
medicaid only include the fungible value of the insurance rather than the total cost to taxpayers of providing the insurance.

Paradoxically, even though the implicit subsidies in the health insurance system look relatively more favorable to the low income population when the MEPS imputations are used, the effect on inequality of including health insurance subsidies in income is bigger when the Census Bureau estimates are used. Between 2001 and 2005 the Gini coefficient of income inequality falls an average of 8.3 percent when the Census Bureau's estimates of insurance value are added to disposable cash and near-cash income and the return on homeowners' net home equity. In the same period, the Gini coefficient falls an average of only 2.4 percent when the MEPS imputations of health spending minus out-of-pocket payment minus premium payments are added to disposable income. For members of households that are headed by someone who is 65 or older the differing effects on inequality even more striking. In this older population the Gini coefficient falls 24.3 percent when the Census Bureau's insurance value estimates are added to net income, but it only falls 8.0 percent when the MEPS imputations of health spending minus out-of-pocket payment minus premium payments are added to net incomes.

The explanation for this difference is straightforward. Even though the MEPS estimates of the net gain from insurance appear quite redistributive in Figures 11 and 16, the actual distribution of income gains that are added to households' incomes are in fact quite variable within each centile of the income distribution (see Figure 7). The Census Bureau imputations of insurance value are much more equal across the insured population (and within each centile of the income distribution). People past age 65 who are insured under medicare are all assigned very similar values of medicare insurance. As our tabulations of the MEPS household survey make clear, however, in any given year the excess of medicare reimbursements over medicare premiums varies widely from person to person. The value of medicare insurance to enrollees varies more than implied by the Census Bureau imputations but far less than the actual excess of medicare reimbursement payments over medicare premiums. Both sets of estimates imply, however, that the value of health insurance represents a bigger proportional boost to the incomes of the low-income population and the aged than it does to the incomes of the affluent and the young.

Figure 17 compares the age profile of income under three income definitions. The income definition that yields the largest relative income difference among age groups is gross 
money income, which is the Census Bureau's standard income definition. The income differences across age groups are reduced under both of the other definitions, which add nearcash income sources and returns on homeowners' net home equity and subtract payroll and income taxes from households' gross money income. In addition, the two alternative income definitions include an estimate of the health consumption that families enjoy in addition to the consumption they can purchase out of after-tax income. Most of the change in relative income favors people who are 65 and older. The additions to measured income have a somewhat more favorable impact on the relative incomes of the aged when they are based on the Census Bureau's estimate of the insurance value of medicare and medicaid and employer contributions to group health plans. On the other hand, the relative incomes of the population between 50 and 64 appear higher when the income estimates include imputations of net insurance gains derived from the MEPS household survey. The relative incomes of the population below age 50 are essentially the same under both sets of estimates of the value of health insurance protection. Under both of the broader income definitions, the relative position of the elderly population is vastly improved compared with its position under the Census Bureau's standard money income definition. Under the standard income definition, every age group past age 65 has below-average income. Under the broader income definitions, the population between 65 and 74 has aboveaverage income and the population older than 75 has an income that is within 10 percent of the population-average income.

\section{Conclusion}

Cash income offers an incomplete picture of the resources available to finance household consumption. Most American families are covered by an insurance plan that pays for some or all of the health care they consume. Only a comparatively small percentage of families pays for the full cost of this insurance out of their cash incomes. As health care has claimed a growing share of consumption, the percentage of care that is financed out of household incomes has declined. Because health care consumption is more important for some groups in the population than others, the growth in spending and changes in the payment system for medical care have reduced the value of standard income measures for assessing relative incomes across age groups and across the income distribution.

This paper has examined the distribution of health consumption and insurance over the decade between 1996 and 2005. It compares the implications of two sets of estimates of effects 
of the current health care system on the distribution of income across persons and across age groups. Both sets of estimates imply that both gross income and disposable cash income significantly understate the resources available to finance household purchases. Both also show that a more complete measure of resources would show less inequality than the income measures that are currently used. The addition of estimates of the value of health insurance to countable incomes reduces measured inequality in the population, because the additions are proportionately much bigger for people at the bottom of the income distribution than they are for people in the middle and at the top. The inclusion of health insurance in the definition of income also has a large impact on the relative income position of the aged, who consume more health care and receive more generous insurance subsidies than the nonaged.

Table 1 summarizes the results of using alternative income definitions for 2001-2005 household incomes. The estimates in the table show the distribution of income under five alternative measures of income: (1) Census money income; (2) Disposable cash and near-cash income (that is, Census money income plus near-cash income minus income and payroll tax payments); (3) Income under definition \#2 plus homeowner's return on net home equity; (4) Income under definition \#3 plus imputations derived from the MEPS of the net gains that households obtain from health insurance; and (5) Income under definition \#3 plus the Census Bureau's imputations of the fungible insurance value of medicare and medicaid and the value of employer contributions to employee health plans. For each definition of income, we measure income as a percent of the median household-size-adjusted income estimated under that definition. We have estimated the distribution of equivalent personal income under these income definitions for the population as a whole and for individuals in three groups of households: households with a head who is under age 55 , households with a head between ages 55 and 64 , and households headed by a person who is 65 or older.

The relative position of aged households is worse under the money income definition than it is under more comprehensive definitions, and the relative income position of aged households is best under the two broadest income definitions. Under the money income definition, both the median and average incomes of aged households are considerably lower than the corresponding income amounts for nonaged households. For example, the top panel in Table 1 shows that the median money income in aged households is 28 percent lower than the overall median income, while the median money income in households headed by someone under 55 is 
3 percent higher than the median money income of the entire population. Under the two broadest definitions of income, both of which include an estimate of the value of health insurance, the median incomes of people in aged households are higher than those of people who are members of households headed by someone who is less than 55. In fact, the income distribution of people in aged households is uniformly higher than that of people in households headed by someone under 55 .

An important goal of U.S. health policy is to improve access to good health insurance among the elderly and low income populations. Although this goal has not been fully achieved, especially among the nonelderly poor, a large percentage of the poor and elderly are now covered by generously subsidized insurance. Under the standard definition of money income, very little of the consumption that is financed by generous health insurance is included in household income. Using a broader income definition that includes these income flows, the relative position of the nation's low income and aged populations is substantially improved. Under the broadest definitions of income we consider here, the economic status of America's aged households appears to be approximately the same if not better than that of nonaged households. 


\section{References}

Bernard, Didem, and Jessica S. Banthin. 2007. "Family-Level Expenditures on Health Care and Insurance Premiums among the U.S. Nonelderly Population, 2004." Research Findings No. 26. (April). Rockville, MD: Agency for Healthcare Research and Quality.

Bosworth, Barry P., Gary Burtless, and Sarah Anders. 2007. "Capital Income Flows and the Relative Well-Being of America's Aged Population.” Center for Retirement Research at Boston College Working Paper \#2007-21. Chestnut Hill, MA: Boston College.

Burtless, Gary. 1996. "Trends in the Level and Distribution of U.S. Living Standards, 19731993." Eastern Economic Journal 22(3) (Summer), pp. 271-90.

Centers for Medicare and Medicaid Services, Office of the Actuary, National Health Statistics Group. 2008. National Health Expenditure Data. http://www.cms.hhs.gov/NationalHealthExpendData/ 02_NationalHealth AccountsHistorical.asp\#TopOfPage (accessed May 9, 2008).

Claxton, Gary, Jon R. Gabel, Bianca DiJulio, Jeremy Pickreign, Heidi Whitmore, Benjamin Finder, Marian Jarlenski, and Samantha Hawkins. 2008. "Health Benefits In 2008: Premiums Moderately Higher, While Enrollment In Consumer-Directed Plans Rises in Small Firms." Health Affairs 27(6) (September), pp. w492-w502.

Cleveland, Robert W. 2005. Alternative Income Estimates in the United States. Current Population Reports, Series P60-228. Washington, DC: U.S. Government Printing Office.

Clingman, Michael, Orlo Nichols, and Chris Chaplain. 2008. Illustrative Benefits for Retired Workers, Disabled Workers, and Survivors Scheduled under Current Law. Actuarial Note 2008.4. Baltimore, MD: Office of the Chief Actuary, U.S. Social Security Administration.

Jacobs, Eva, and Stephanie Shipp. 1990. "How Family Spending Has Changed in the U.S." Monthly Labor Review 113(3) (March), pp. 20-27.

O’Sullivan, Jennifer. 2004. Medicare Part B Premiums. CRS Report for Congress RL32582. Washington, DC: U.S. Congressional Research Service.

Roemer, Marc I. 2000. "Assessing the Quality of the March Current Population Survey and the Survey of Income and Program Participation Income Estimates, 1990-1996.” (June 16, 2000) Suitland, MD: Income Surveys Branch, Housing and Household Economic Statistics Division, U.S. Census Bureau.

Ruser, John, Adrienne Pilot, and Charles Nelson. 2004. "Alternative Measures of Household Income: BEA Personal Income, CPS Money Income, and Beyond." Paper prepared for the Federal Economic Statistics Advisory Committee (December 14, 2004). Washington, D.C.: U.S. Bureau of Economic Analysis.

Sing, Merrile, Jessica S. Banthin, Thomas M. Selden, Cathy A. Cowan, and Sean P. Keehan. 2006. "Reconciling Medical Expenditure Estimates from the MEPS and NHEA, 2002." Health Care Financing Review 28(1) (Fall), pp. 25-40.

U.S. Bureau of the Census. 1993. Measuring the Effect of Benefits and Taxes on Income and Poverty: 1992. Current Population Reports, Series P60-1986-RD. Washington, DC: U.S. Government Printing Office. 


\section{Appendix \\ Imputing Health Care Expenditures and Premiums to CPS families}

In order to calculate our broader income definition that includes health care related variables, we had to impute health care expenditures and insurance premiums to each family in the CPS, since these variables are absent from the CPS files. Given that the primary insurance unit of group insurance plans is a family, we took advantage of the fact that the MEPS files provide an indicator of CPS-like families and matched the two surveys at this family level.

Before constructing our matching key variables for family level matching units in the MEPS and the CPS, we restricted the MEPS sample of persons so that it is similar to the March CPS sample. Both samples represent the civilian non-institutionalized population. The March CPS sample consists of persons who are in families and/or household units at the date of the March interview. We restricted our MEPS sample to persons who were present in MEPS families and/or household units on December 31 of the calendar year.

We defined eleven key variables to match on eleven levels. The key variables and their definitions are listed below:

\section{KeyVar1 Family composition}

1 - Family head alone

2 - Married couple alone with at most one person 65 or older

3 - Married couple with only their own children with youngest child under 5

4 - Married couple with only their own children with youngest child between 5 and 17

5 - Family head alone with only own children with youngest child under 5

6 - Family head alone with only own children with youngest child between 5 and 17

7 - Married couple with other relatives and youngest child under 5 (no matter whose child)

8 - Married couple with other relatives and youngest child between 5 and 17 (no matter whose child)

9 - Married couple with adults (own children, other relatives)

10 - Family head alone with other relatives and youngest child under 5 (no matter whose child)

11 - Head alone with other relatives and youngest child between 5 and 17 (no matter whose child)

12 - Head alone with other adults (own children, other relatives)

13 - Married couple alone with both persons 65 or older

KeyVar2 Family size adjusted gross money income quintile

$1-1^{\text {st }}$ quintile

$2-2^{\text {nd }}$ quintile

$3-3^{\text {rd }}$ quintile

$4-4^{\text {th }}$ quintile

$5-5^{\text {th }}$ quintile

KeyVar3 Employment status of family head or of spouse of head

1 - Employed

2 - Not employed

\section{KeyVar4 Covered by Medicare}

1 - At least one person in family covered by Medicare but no non-group insurance

$2-1$ does not apply and at least one person in family covered by Medicare and non-group insurance 
$3-1$ and 2 do not apply

\section{KeyVar5 Covered by Medicaid}

1 - At least one person covered by Medicaid

2 - No person in family covered by Medicaid

\section{KeyVar6 Covered by private insurance}

1 - At least one person in family covered by group coverage

$2-1$ does not apply and at least one person in family covered by only non group coverage

$3-1$ and 2 do not apply

\section{KeyVar7 At least one sick person in family}

1 - At least one person in family with poor or fair health

0 - No person in family with poor or fair health

\section{KeyVar8 At least one person in family 65 or older}

1 - At least one person in family 65 or older

0 - No person in family 65 or older

\section{KeyVar9 Age of family head}

$1-0-29$

$2-30-39$

$3-40-49$

$4-50-59$

$5-60-69$

$6-70+$

\section{KeyVar10 Covered by Tricare}

1 - At least one person in family covered by Tricare

0 - No person in family covered by Tricare

KeyVar11 Covered by other public insurance

1 - At least one person in family covered by other public insurance

0 - No person covered by other public insurance

The 11 matching levels are as follows:

Matching Level 1

KeyVar1 KeyVar2 KeyVar3 KeyVar4 KeyVar5 KeyVar6 KeyVar7 KeyVar8 KeyVar9 KeyVar10 KeyVar11

Matching Level 2

KeyVar1 KeyVar2 KeyVar3 KeyVar4 KeyVar5 KeyVar6 KeyVar7 KeyVar8 KeyVar9 KeyVar10

Matching Level 3

KeyVar1 KeyVar2 KeyVar3 KeyVar4 KeyVar5 KeyVar6 KeyVar7 KeyVar8 KeyVar9

Matching Level 4

KeyVar1 KeyVar2 KeyVar3 KeyVar4 KeyVar5 KeyVar6 KeyVar7 KeyVar8 
Matching Level 5

KeyVar1 KeyVar2 KeyVar3 KeyVar4 KeyVar5 KeyVar6 KeyVar7

Matching Level 6

KeyVar1 KeyVar2 KeyVar3 KeyVar4 KeyVar5 KeyVar6

Matching Level 7

KeyVar1 KeyVar2 KeyVar3 KeyVar4 KeyVar5

Matching Level 8

KeyVar1 KeyVar2 KeyVar3 KeyVar4

Matching Level 9

KeyVar1 KeyVar2 KeyVar3

Matching Level 10

KeyVar1 KeyVar2

Matching Level 11

KeyVar1

The quality of our statistical matches is displayed in Appendix Table 1. The best match is achieved if all key variables of the target family are matched to all key variables of the donor family. In the following table, this level of match is indicated by a " 1 ". On every subsequent matching level we drop the least important key variable. For instance, in a level-2 match, all of the key variables except the least important one are matched. 
Appendix Table 1

Matching Levels for CPS Family Units

\begin{tabular}{|c|c|c|c|c|c|c|c|c|c|c|c|}
\hline year & Level & No of Obs. & $\%$ & year & Level & No of Obs. & $\%$ & year & Level & No of Obs. & $\%$ \\
\hline \multirow[t]{12}{*}{1996} & 1 & 48,806 & $86.0 \%$ & 2000 & 1 & 49,064 & $86.9 \%$ & 2004 & 1 & 76,827 & $88.2 \%$ \\
\hline & 2 & 314 & $0.6 \%$ & & 2 & 248 & $0.4 \%$ & & 2 & 701 & $0.8 \%$ \\
\hline & 3 & 438 & $0.8 \%$ & & 3 & 430 & $0.8 \%$ & & 3 & 662 & $0.8 \%$ \\
\hline & 4 & 3,689 & $6.5 \%$ & & 4 & 3,389 & $6.0 \%$ & & 4 & 4,585 & $5.3 \%$ \\
\hline & 5 & 734 & $1.3 \%$ & & 5 & 724 & $1.3 \%$ & & 5 & 1,140 & $1.3 \%$ \\
\hline & 6 & 1,221 & $2.2 \%$ & & 6 & 1,003 & $1.8 \%$ & & 6 & 1,285 & $1.5 \%$ \\
\hline & 7 & 875 & $1.5 \%$ & & 7 & 977 & $1.7 \%$ & & 7 & 1,150 & $1.3 \%$ \\
\hline & 8 & 355 & $0.6 \%$ & & 8 & 376 & $0.7 \%$ & & 8 & 249 & $0.3 \%$ \\
\hline & 9 & 270 & $0.5 \%$ & & 9 & 216 & $0.4 \%$ & & 9 & 448 & $0.5 \%$ \\
\hline & 10 & 38 & $0.1 \%$ & & 10 & 25 & $0.0 \%$ & & 10 & 57 & $0.1 \%$ \\
\hline & 11 & 0 & $0.0 \%$ & & 11 & 2 & $0.0 \%$ & & 11 & 0 & $0.0 \%$ \\
\hline & Total & 56,740 & $100.0 \%$ & & Total & 56,454 & $100.0 \%$ & & Total & 87,104 & $100.0 \%$ \\
\hline \multirow[t]{12}{*}{1997} & 1 & 50,563 & $89.1 \%$ & 2001 & 1 & 79,138 & $88.9 \%$ & 2005 & 1 & 76,146 & $87.7 \%$ \\
\hline & 2 & 282 & $0.5 \%$ & & 2 & 488 & $0.5 \%$ & & 2 & 696 & $0.8 \%$ \\
\hline & 3 & 506 & $0.9 \%$ & & 3 & 699 & $0.8 \%$ & & 3 & 727 & $0.8 \%$ \\
\hline & 4 & 2,819 & $5.0 \%$ & & 4 & 4,562 & $5.1 \%$ & & 4 & 4,878 & $5.6 \%$ \\
\hline & 5 & 624 & $1.1 \%$ & & 5 & 929 & $1.0 \%$ & & 5 & 1,133 & $1.3 \%$ \\
\hline & 6 & 870 & $1.5 \%$ & & 6 & 1,282 & $1.4 \%$ & & 6 & 1,358 & $1.6 \%$ \\
\hline & 7 & 719 & $1.3 \%$ & & 7 & 1,181 & $1.3 \%$ & & 7 & 1,230 & $1.4 \%$ \\
\hline & 8 & 188 & $0.3 \%$ & & 8 & 367 & $0.4 \%$ & & 8 & 336 & $0.4 \%$ \\
\hline & 9 & 152 & $0.3 \%$ & & 9 & 325 & $0.4 \%$ & & 9 & 295 & $0.3 \%$ \\
\hline & 10 & 22 & $0.0 \%$ & & 10 & 43 & $0.0 \%$ & & 10 & 41 & $0.0 \%$ \\
\hline & 11 & 0 & $0.0 \%$ & & 11 & 0 & $0.0 \%$ & & 11 & 0 & $0.0 \%$ \\
\hline & Total & 56,745 & $100.0 \%$ & & Total & 89,014 & $100.0 \%$ & & Total & 86,840 & $100.0 \%$ \\
\hline \multirow[t]{12}{*}{1998} & 1 & 49,901 & $87.1 \%$ & 2002 & 1 & 79,245 & $89.0 \%$ & & & & \\
\hline & 2 & 271 & $0.5 \%$ & & 2 & 668 & $0.8 \%$ & & & & \\
\hline & 3 & 493 & $0.9 \%$ & & 3 & 622 & $0.7 \%$ & & & & \\
\hline & 4 & 3,613 & $6.3 \%$ & & 4 & 4,421 & $5.0 \%$ & & & & \\
\hline & 5 & 606 & $1.1 \%$ & & 5 & 1,054 & $1.2 \%$ & & & & \\
\hline & 6 & 1,105 & $1.9 \%$ & & 6 & 1,232 & $1.4 \%$ & & & & \\
\hline & 7 & 867 & $1.5 \%$ & & 7 & 1,118 & $1.3 \%$ & & & & \\
\hline & 8 & 247 & $0.4 \%$ & & 8 & 360 & $0.4 \%$ & & & & \\
\hline & 9 & 173 & $0.3 \%$ & & 9 & 295 & $0.3 \%$ & & & & \\
\hline & 10 & 21 & $0.0 \%$ & & 10 & 37 & $0.0 \%$ & & & & \\
\hline & 11 & 0 & $0.0 \%$ & & 11 & 0 & $0.0 \%$ & & & & \\
\hline & Total & 57,297 & $100.0 \%$ & & Total & 89,052 & $100.0 \%$ & & & & \\
\hline \multirow[t]{12}{*}{1999} & 1 & 50,601 & $87.2 \%$ & 2003 & 1 & 77,593 & $88.3 \%$ & & & & \\
\hline & 2 & 211 & $0.4 \%$ & & 2 & 508 & $0.6 \%$ & & & & \\
\hline & 3 & 459 & $0.8 \%$ & & 3 & 686 & $0.8 \%$ & & & & \\
\hline & 4 & 3,383 & $5.8 \%$ & & 4 & 4,634 & $5.3 \%$ & & & & \\
\hline & 5 & 776 & $1.3 \%$ & & 5 & 1,008 & $1.1 \%$ & & & & \\
\hline & 6 & 1,108 & $1.9 \%$ & & 6 & 1,312 & $1.5 \%$ & & & & \\
\hline & 7 & 925 & $1.6 \%$ & & 7 & 1,306 & $1.5 \%$ & & & & \\
\hline & 8 & 300 & $0.5 \%$ & & 8 & 390 & $0.4 \%$ & & & & \\
\hline & 9 & 251 & $0.4 \%$ & & 9 & 372 & $0.4 \%$ & & & & \\
\hline & 10 & 33 & $0.1 \%$ & & 10 & 80 & $0.1 \%$ & & & & \\
\hline & 11 & 6 & $0.0 \%$ & & 11 & 0 & $0.0 \%$ & & & & \\
\hline & Total & 58,053 & $100.0 \%$ & & Total & 87,889 & $100.0 \%$ & & & & \\
\hline
\end{tabular}


Table 1. Relative Income at Selected Points in the Income Distribution under Alternative Definitions of Income, by Age of Household Head: 2001-2005 Averages

Median income $=100$

\begin{tabular}{|c|c|c|c|c|c|c|c|c|}
\hline & \multicolumn{7}{|c|}{ Percentile of income distribution } & \multirow{2}{*}{$\begin{array}{c}\text { Overall } \\
\text { Mean }\end{array}$} \\
\hline & 5 & 10 & 25 & $\mathbf{5 0}$ & 75 & 90 & 95 & \\
\hline & \multicolumn{8}{|c|}{ Gross money income } \\
\hline All households & 18 & 29 & 55 & 100 & 164 & 249 & 328 & 130 \\
\hline \multicolumn{9}{|l|}{ Households with heads -- } \\
\hline Age less than 55 & 16 & 28 & 57 & 103 & 165 & 246 & 322 & 131 \\
\hline Age 55-64 & 21 & 34 & 68 & 122 & 200 & 305 & 401 & 159 \\
\hline \multirow[t]{2}{*}{ Age 65 and older } & 22 & 29 & 44 & 72 & 121 & 202 & 274 & 101 \\
\hline & \multicolumn{8}{|c|}{ Disposable cash and near-cash income } \\
\hline All households & 24 & 36 & 60 & 100 & 152 & 216 & 274 & 121 \\
\hline \multicolumn{9}{|l|}{ Households with heads -- } \\
\hline Age less than 55 & 23 & 36 & 62 & 101 & 151 & 212 & 267 & 121 \\
\hline Age 55-64 & 26 & 40 & 72 & 119 & 181 & 258 & 324 & 144 \\
\hline \multirow[t]{2}{*}{ Age 65 and older } & 26 & 34 & 51 & 80 & 126 & 192 & 251 & 102 \\
\hline & \multicolumn{8}{|c|}{ Disposable income + Return on net home equity } \\
\hline All households & 25 & 37 & 61 & 100 & 151 & 213 & 269 & 120 \\
\hline \multicolumn{9}{|l|}{ Households with heads -- } \\
\hline Age less than 55 & 25 & 38 & 64 & 106 & 158 & 221 & 276 & 126 \\
\hline Age 55-64 & 29 & 42 & 74 & 121 & 182 & 257 & 320 & 145 \\
\hline \multirow[t]{2}{*}{ Age 65 and older } & 29 & 38 & 57 & 87 & 133 & 197 & 254 & 107 \\
\hline & \multicolumn{8}{|c|}{ Disposable income + Return on net home equity + Imputation of insurance gain (MEPS) } \\
\hline All households & 28 & 39 & 62 & 100 & 149 & 210 & 264 & 119 \\
\hline \multicolumn{9}{|l|}{ Households with heads -- } \\
\hline Age less than 55 & 26 & 37 & 60 & 97 & 144 & 200 & 251 & 115 \\
\hline Age 55-64 & 33 & 47 & 77 & 123 & 181 & 253 & 315 & 145 \\
\hline \multirow[t]{2}{*}{ Age 65 and older } & 32 & 42 & 64 & 98 & 146 & 215 & 270 & 118 \\
\hline & \multicolumn{8}{|c|}{ Disposable income + Return on net home equity + Imputation of insurance gain (CPS) } \\
\hline All households & 31 & 43 & 66 & 100 & 145 & 201 & 250 & 117 \\
\hline Households with heads -- & & & & & & & & \\
\hline Age less than 55 & 28 & 40 & 62 & 97 & 141 & 194 & 241 & 113 \\
\hline Age 55-64 & 35 & 50 & 78 & 118 & 172 & 239 & 295 & 139 \\
\hline Age 65 and older & 47 & 57 & 75 & 102 & 143 & 199 & 248 & 120 \\
\hline
\end{tabular}

Note: Calculations are performed using "equivalent" or household-size-adjusted incomes for each household. Entries show equivalent income measured as a percent of the median size-adjusted income under the indicated income definition.

Source: Authors' tabulations of 2002-2006 March CPS files. The 2001-2005 MEPS household files were used to derive imputations of net gains to household equivalent income from health insurance in rows 13 through 16 in the table. 
Figure 1. Consumption of Health Care as a Percent of Total Personal Consumption Expenditures, 1960-2007

Percent of total personal consumption expenditures

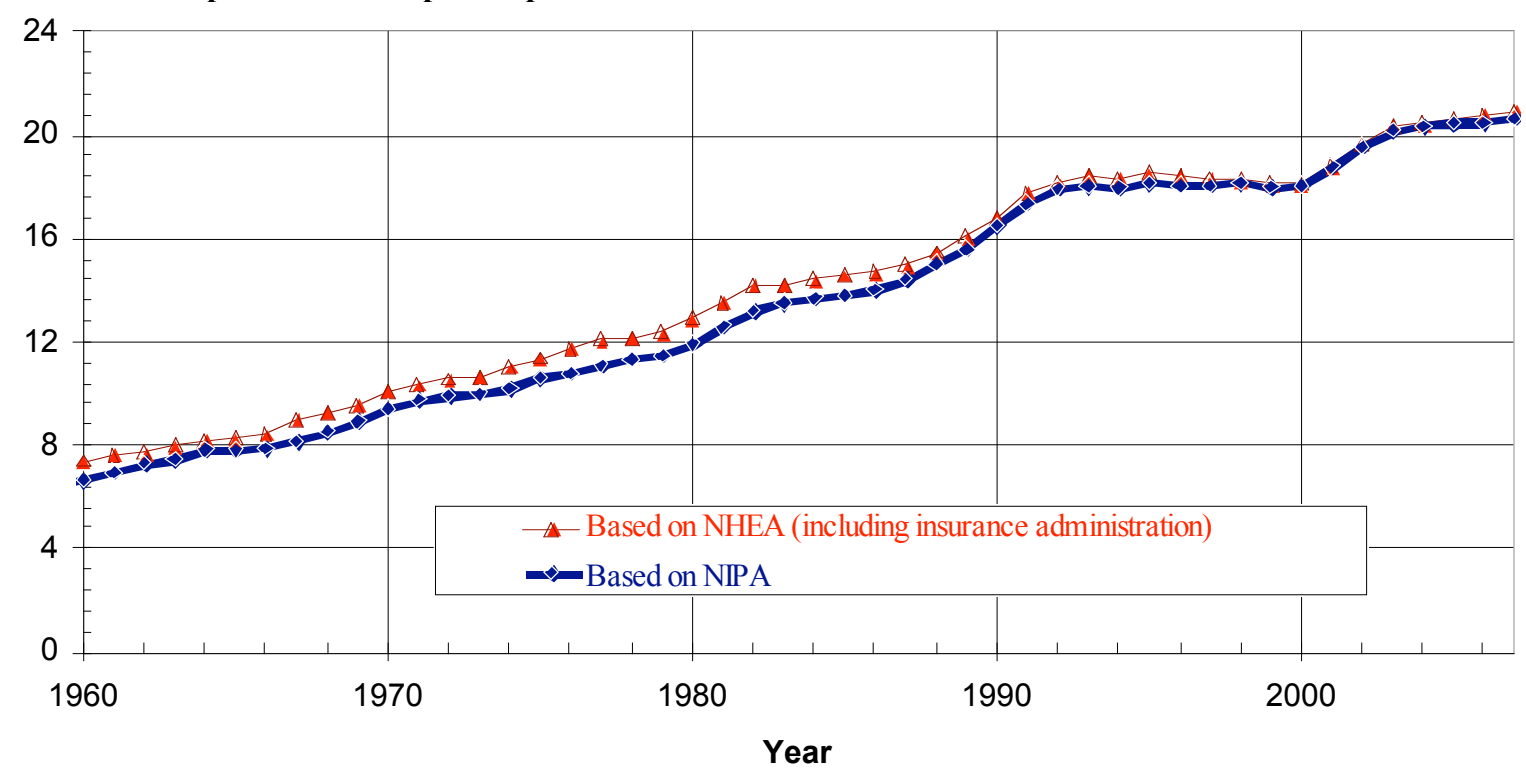

Source: Authors' tabulations of U.S. National Income and Product Account statistics and National Health Expenditure Accounts.

Figure 2. Employer and Government Payments for Health Insurance as a Percent of Personal Consumption and Household Income, 1960-2007

$1 /$

Percent

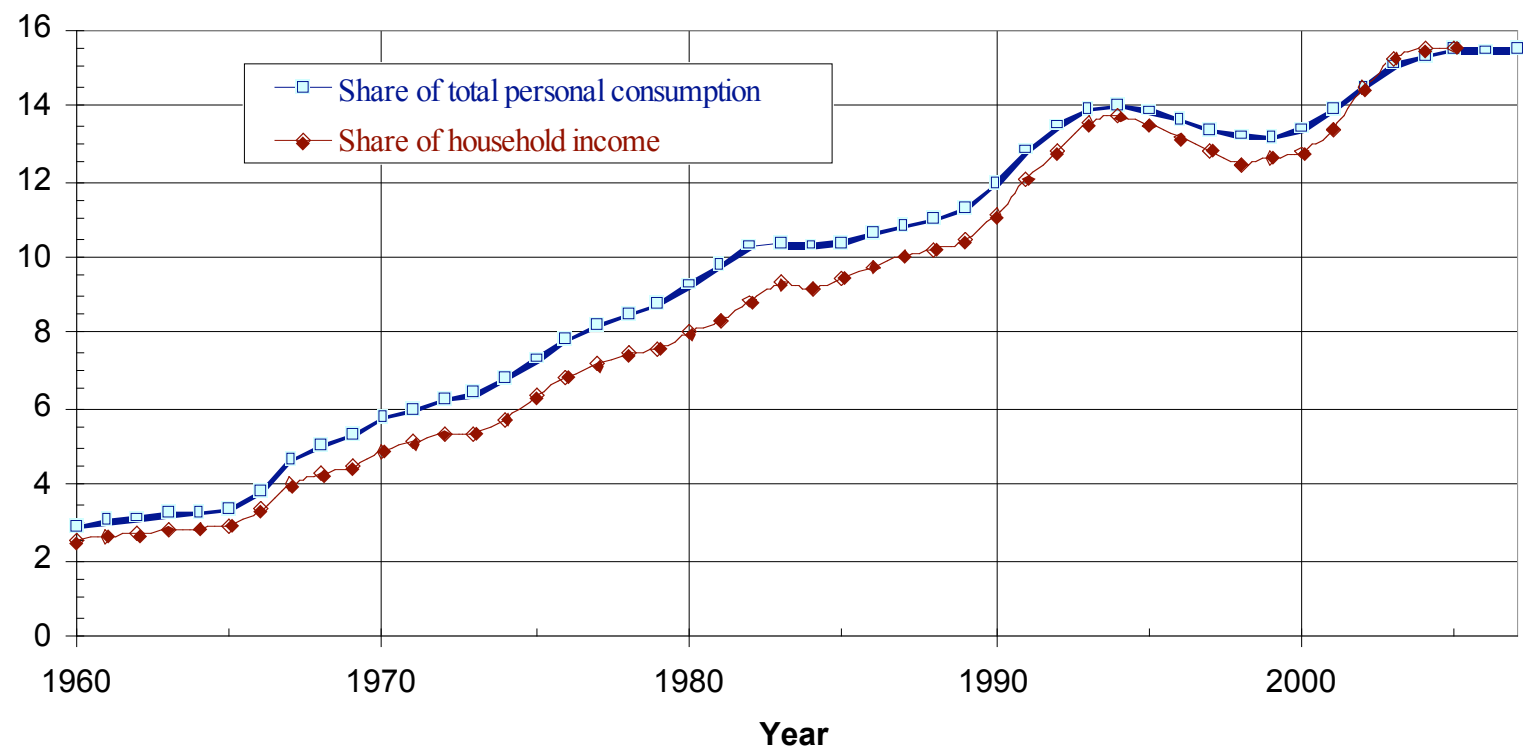

$1 /$ "Household income" is measured using the Census Bureau's definition of gross "money income."

Source: Authors' estimates based on U.S. National Income and Product Account statistics and National Health Expenditure Accounts. 
Figure 3. Relation of Health Status, Income, and Health Care Consumption, 19962005

Total spending per person on health care:

Constant 2005 dollars

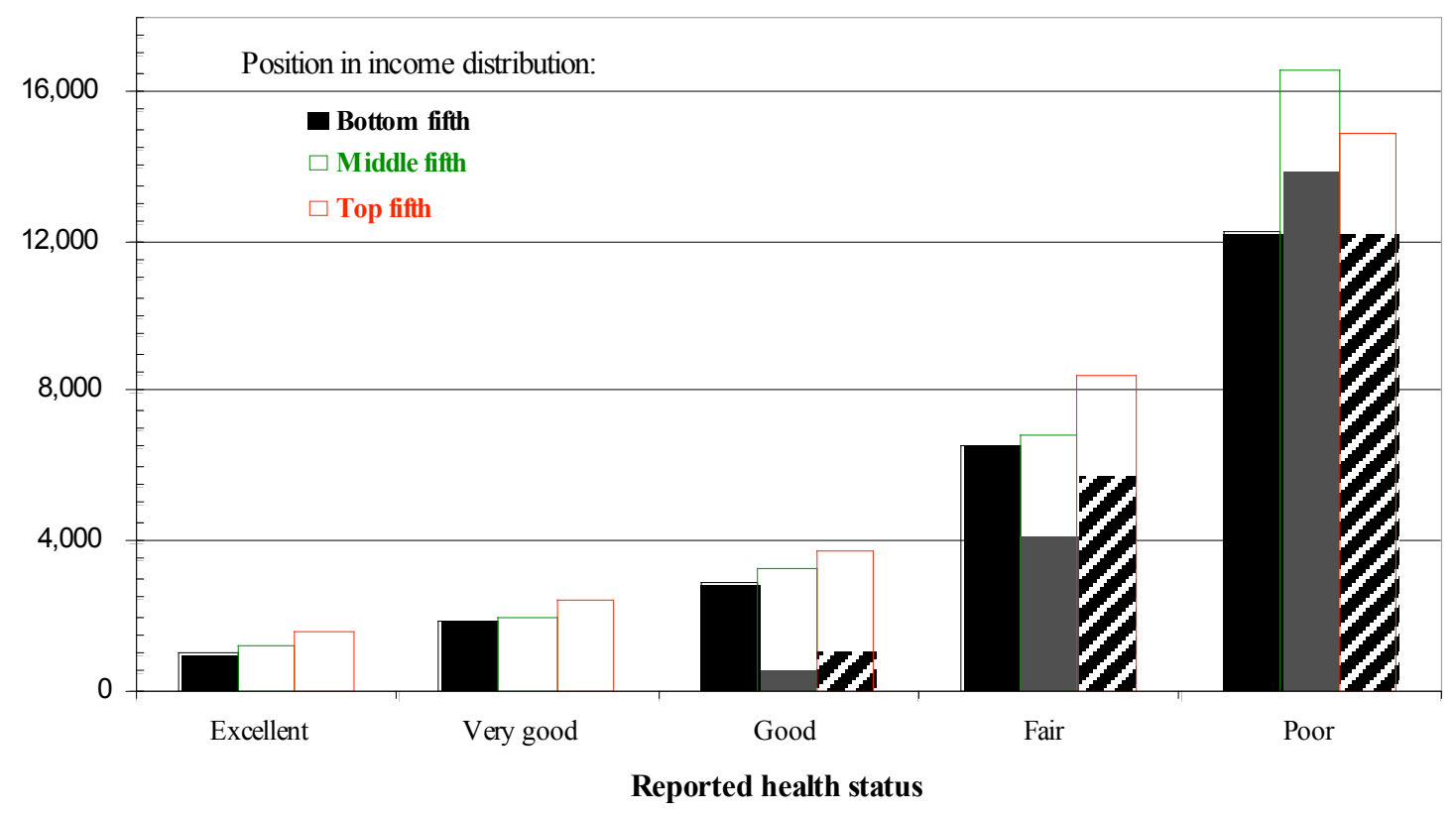

Source: Authors' tabulations of 1996-2005 MEPS household files.

Figure 4. Relation of Health Status, Age, and Income, 1996-2005

Percent in poor health

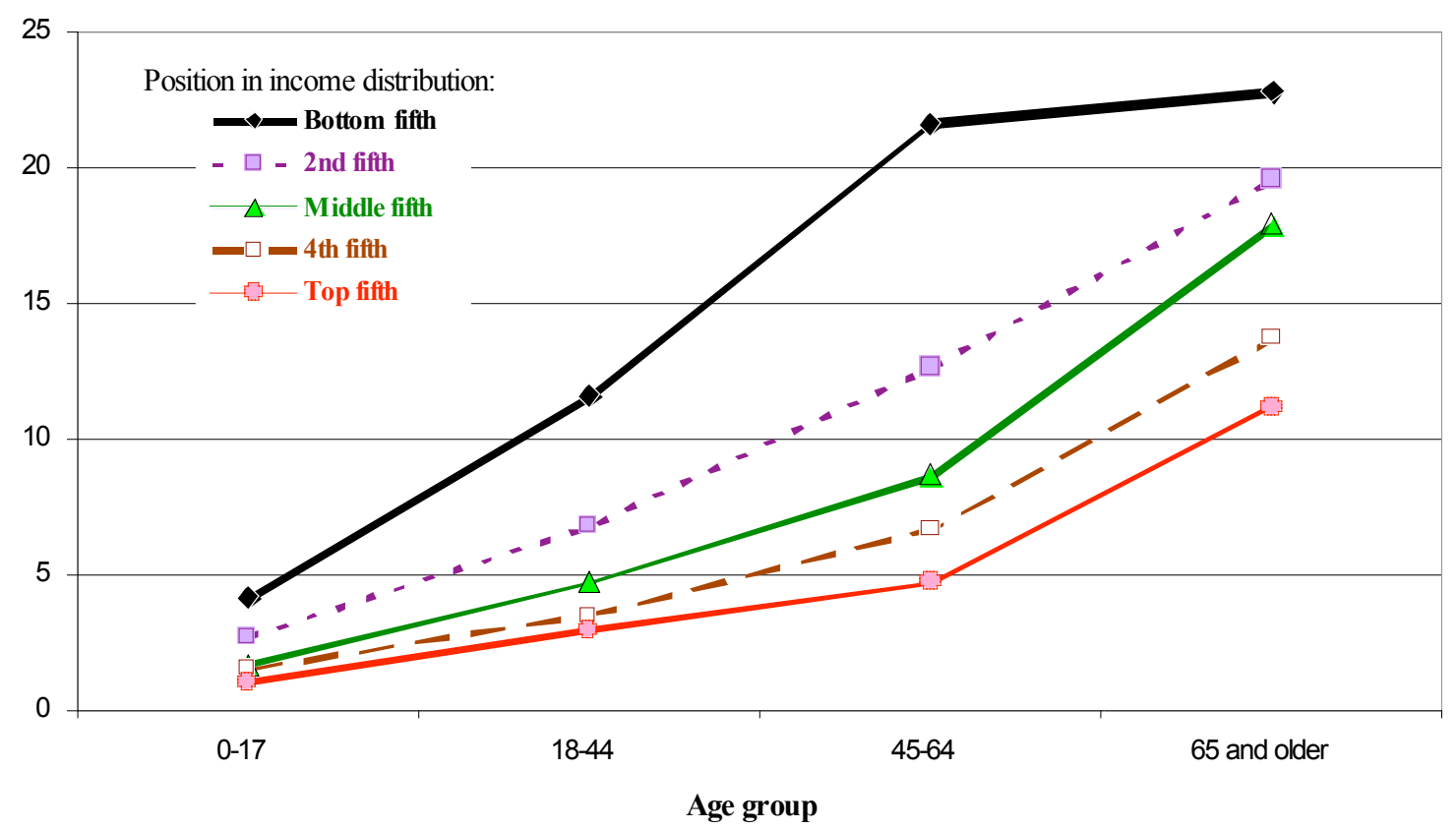

Source: Authors' tabulations of 1996-2005 MEPS household files. 
Figure 5. Quantile Regression Estimates of Total Health Care Spending among Persons in Middle Fifth of Size-adjusted Income Distribution, by Health Status, 2001-2005

Annual spending per person on health care:

\section{Constant 2005 dollars}

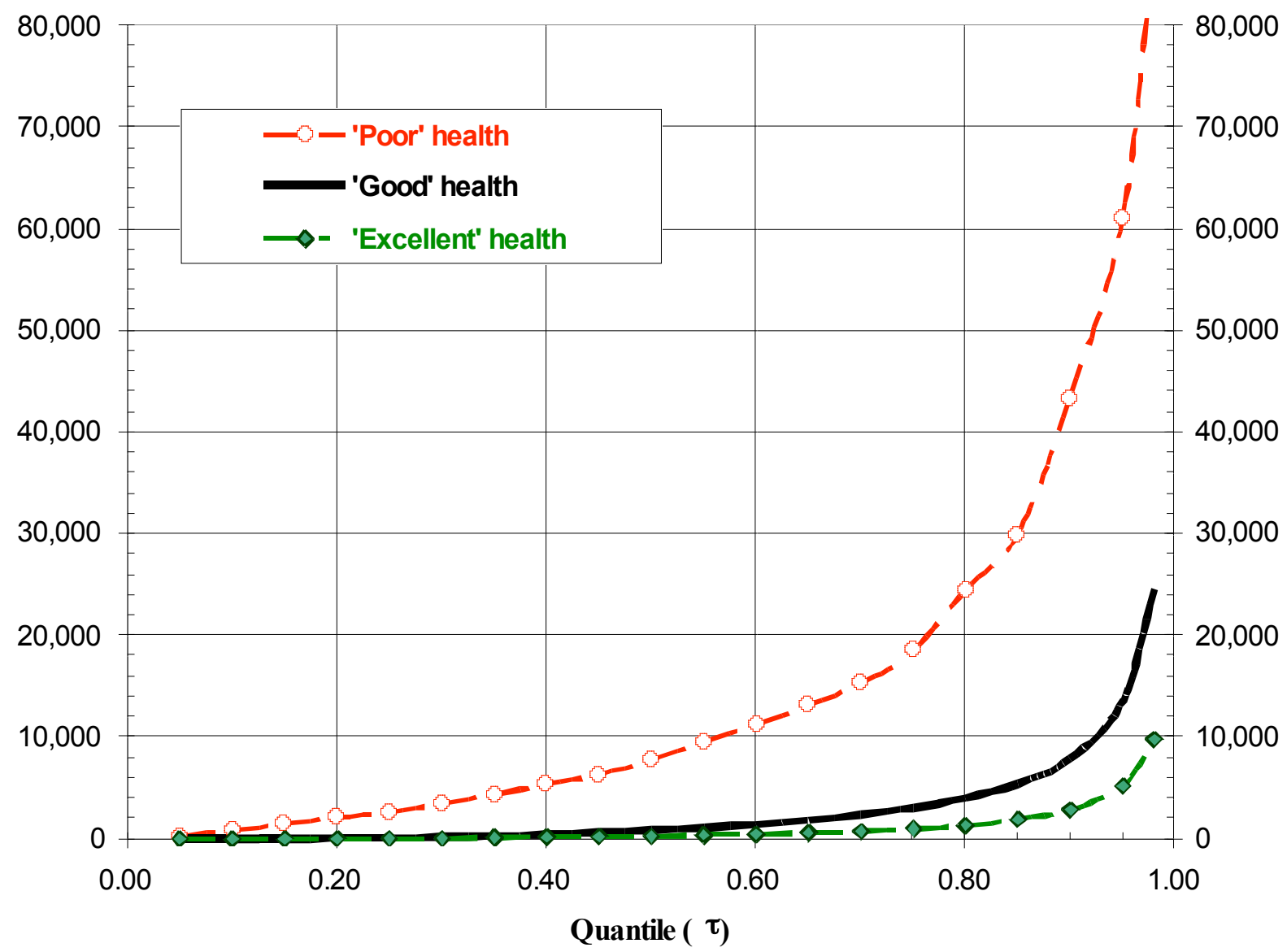

Note: Spending amounts are converted to 2005 dollars using the PCE medical deflator.

Source: Authors' tabulations of 2001-2005 MEPS household files. 
Figure 6. Quantile Regression Estimates of Out-of-pocket Health Spending among Persons in Middle Fifth of Size-adjusted Income Distribution, by Health Status, 2001-2005

Medical out-of-pocket spending per person, excluding premiums:

Constant 2005 dollars

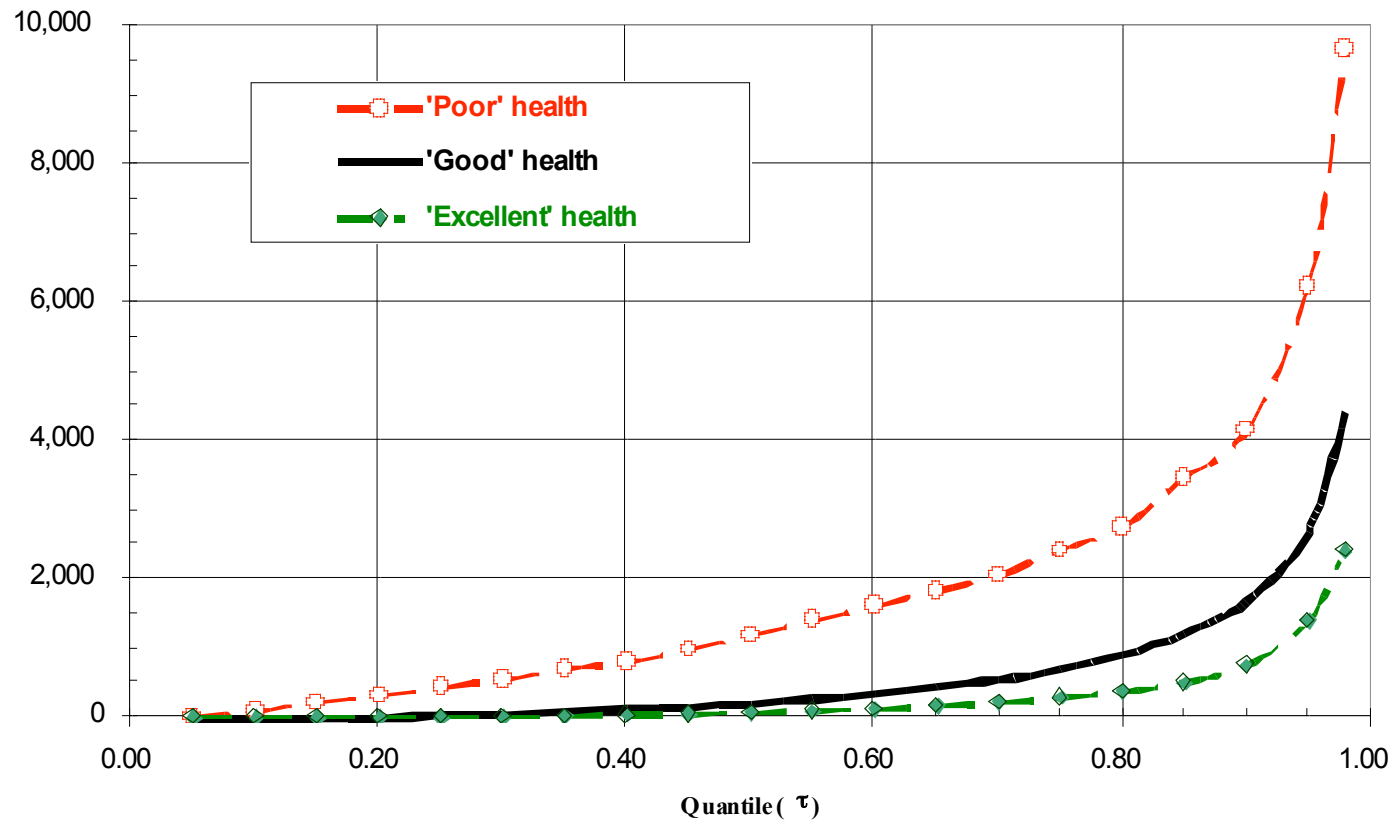

Out-of-pocket spending on premiums, per person:

Constant 2005 dollars

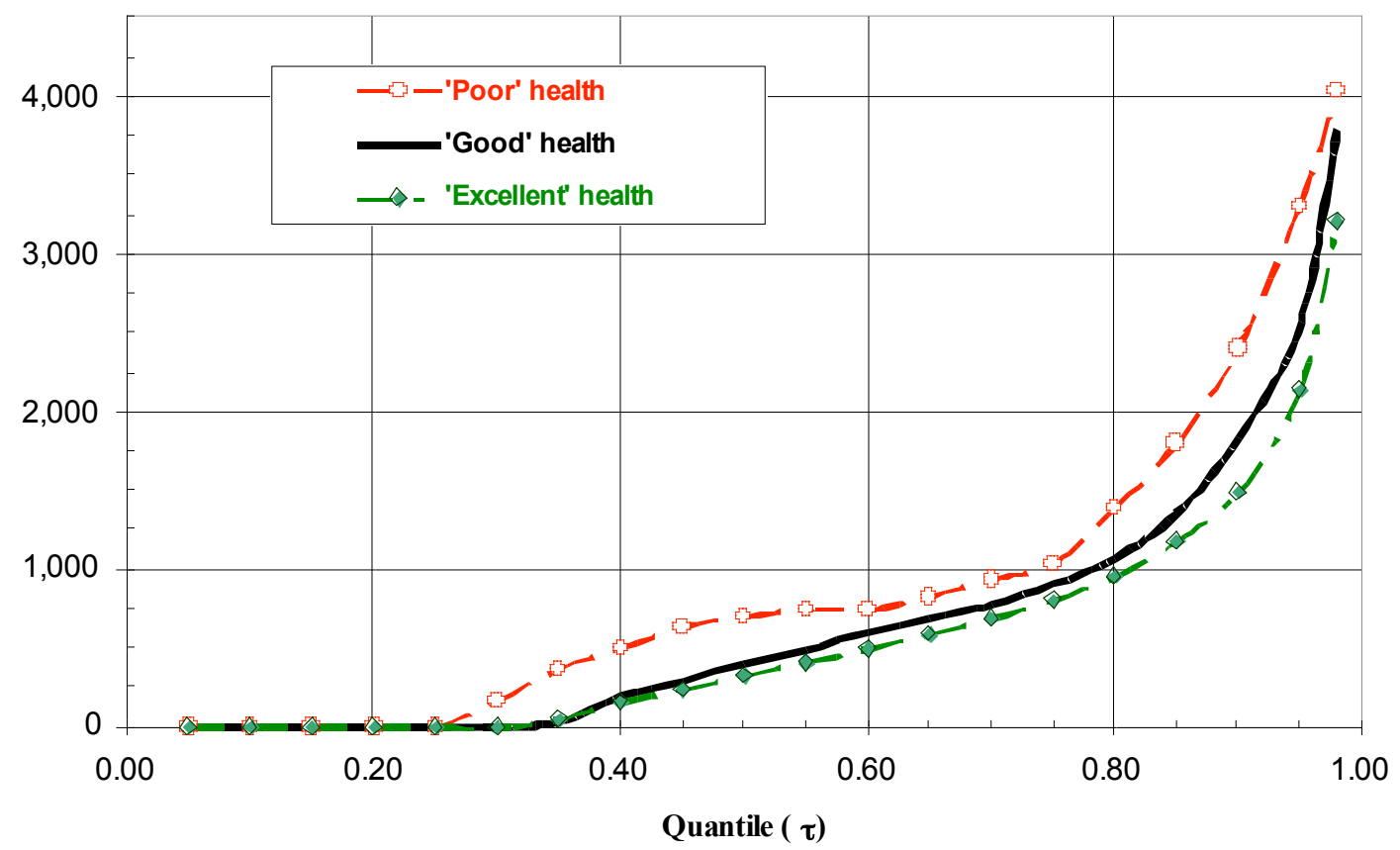

Note: Spending amountsare converted to 2005 dollarsusing the CPI-U-RS deflator.

Source: Authors' tabulations of 2001-2005 MEPS household files. 
Figure 7. Quantile Regression Estimates of Net Gains or Losses from Health Insurance among Persons in Middle Fifth of Income Distribution, by Health Status, 2001-2005

Net gain or loss from insurance, per person:

Constant 2005 dollars $(0<\quad \tau<0.5)$

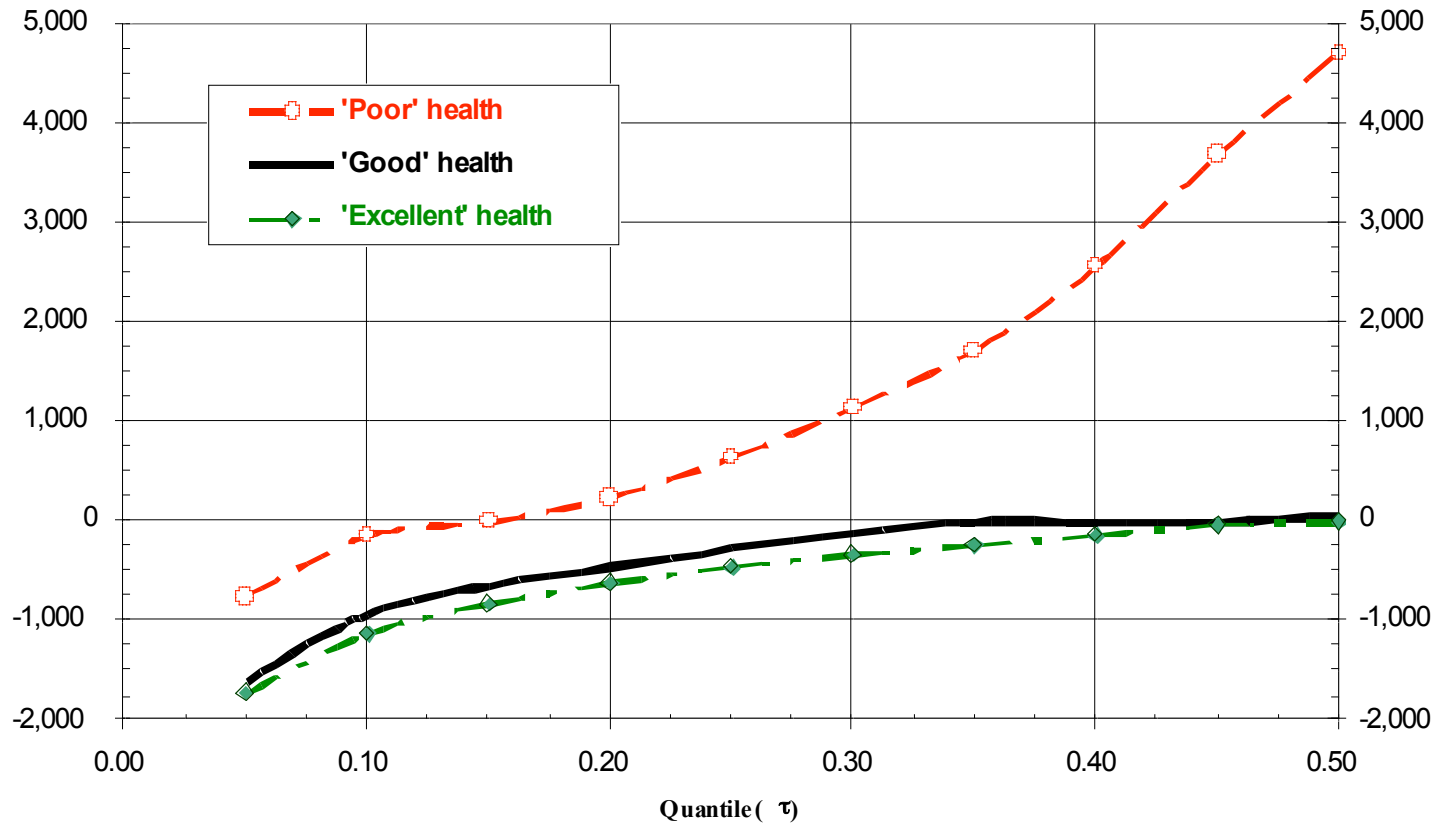

Net gain or loss from insurance, per person:

Constant 2005 dollars $(0.5<\quad \tau<1.0)$

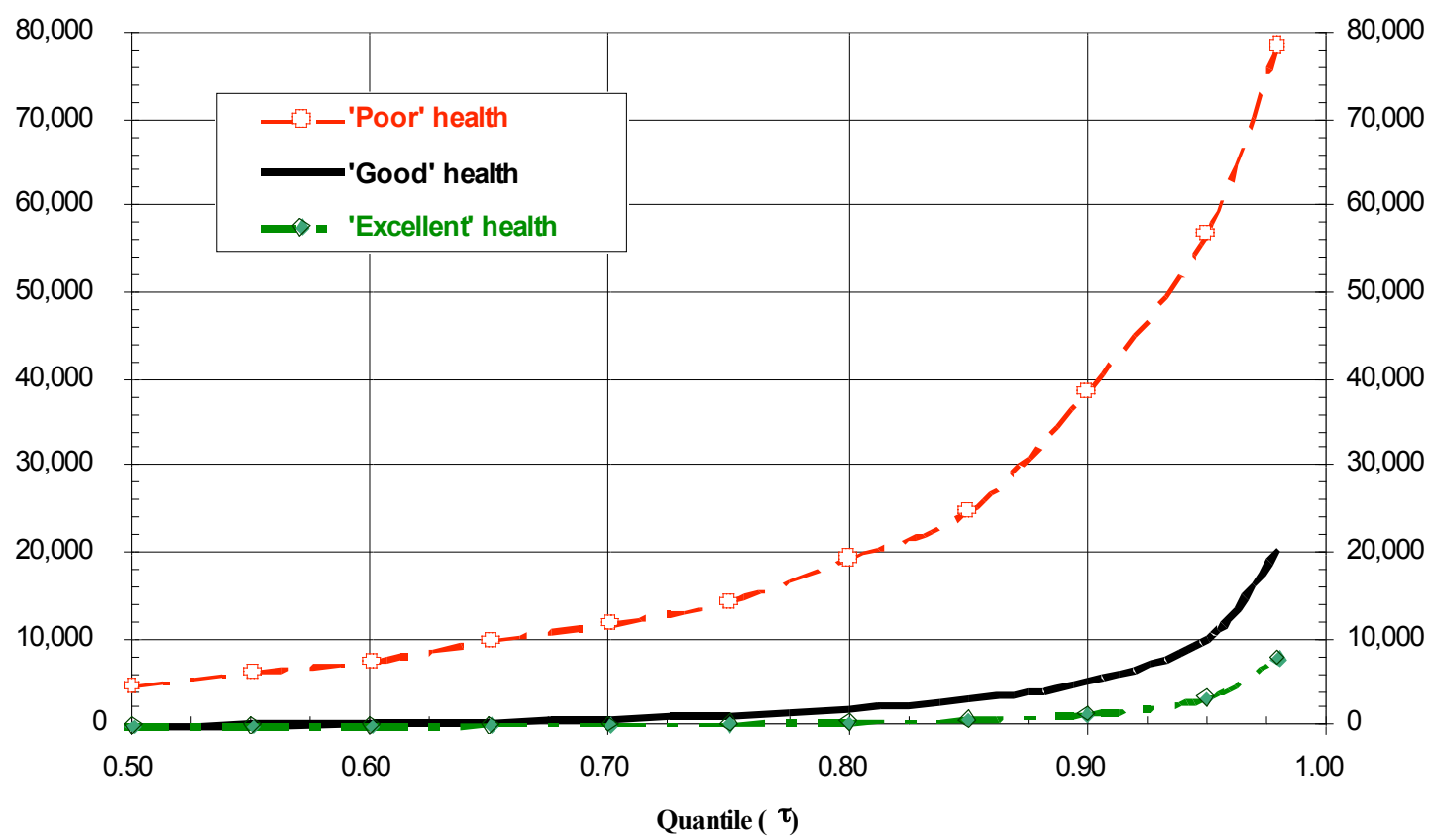

Note: 'Net gain or loss from health insurance' isall reimbursement paymentsmade by insurance plansminusperson'spremium payments. Spending amounts are converted to 2005 dollars using the CPI-U-RS deflator.

Source: Authors' tabulations of 2001-2005 MEPS household files. 
Figure 8. Consumption of Health Care as a Percent of Gross Money Income by Age Group, 1996-2000 and 2001-2005

Total health consumption as percent of gross money income

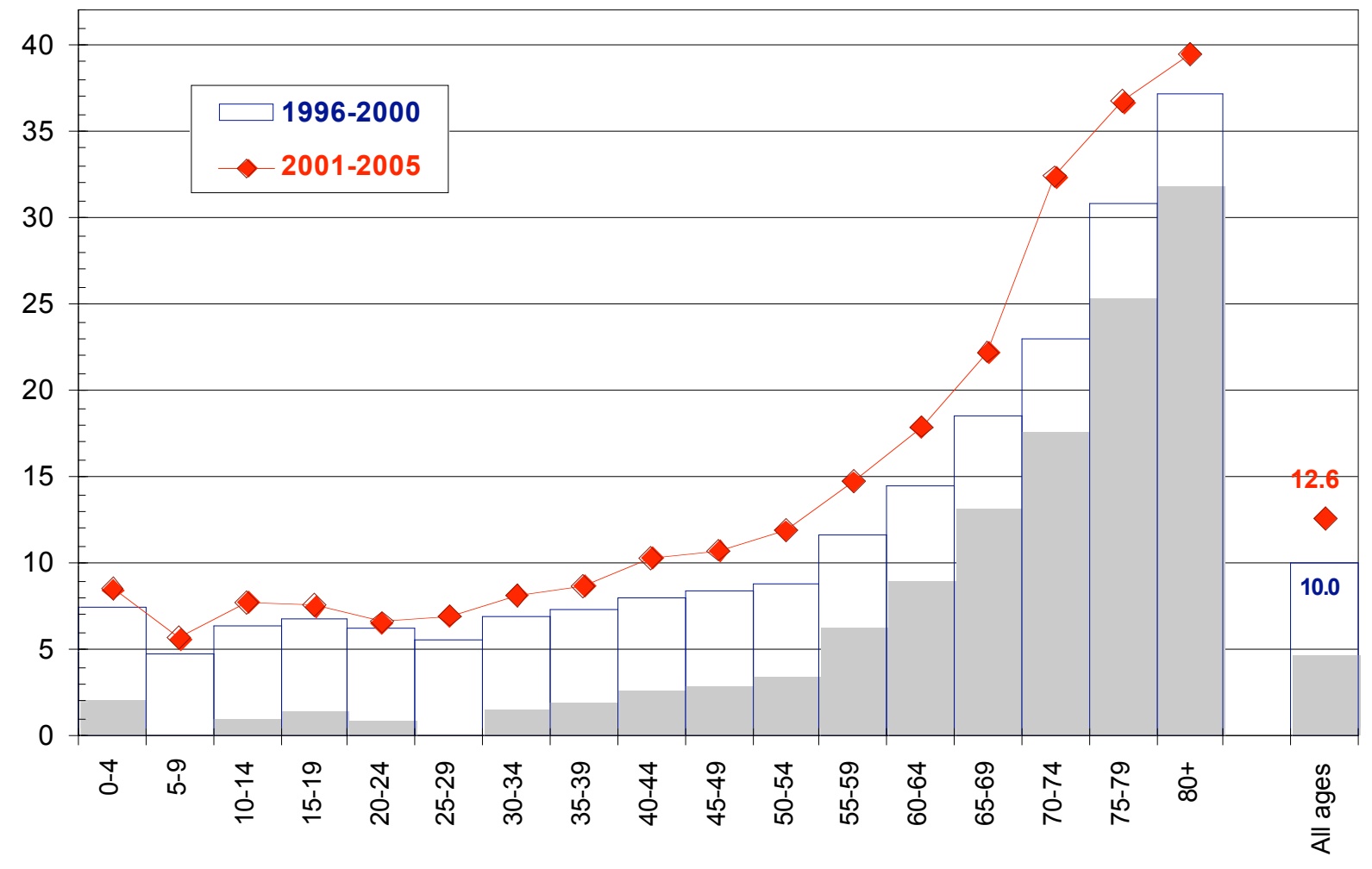

Age group

Source: Authors' tabulations of 1996-2005 MEPS household files. 
Figure 9. Consumption and Financing of Health Care as a Percent of Gross Money Income, 2001-2005

Spending on health care and insurance as percent of gross household income

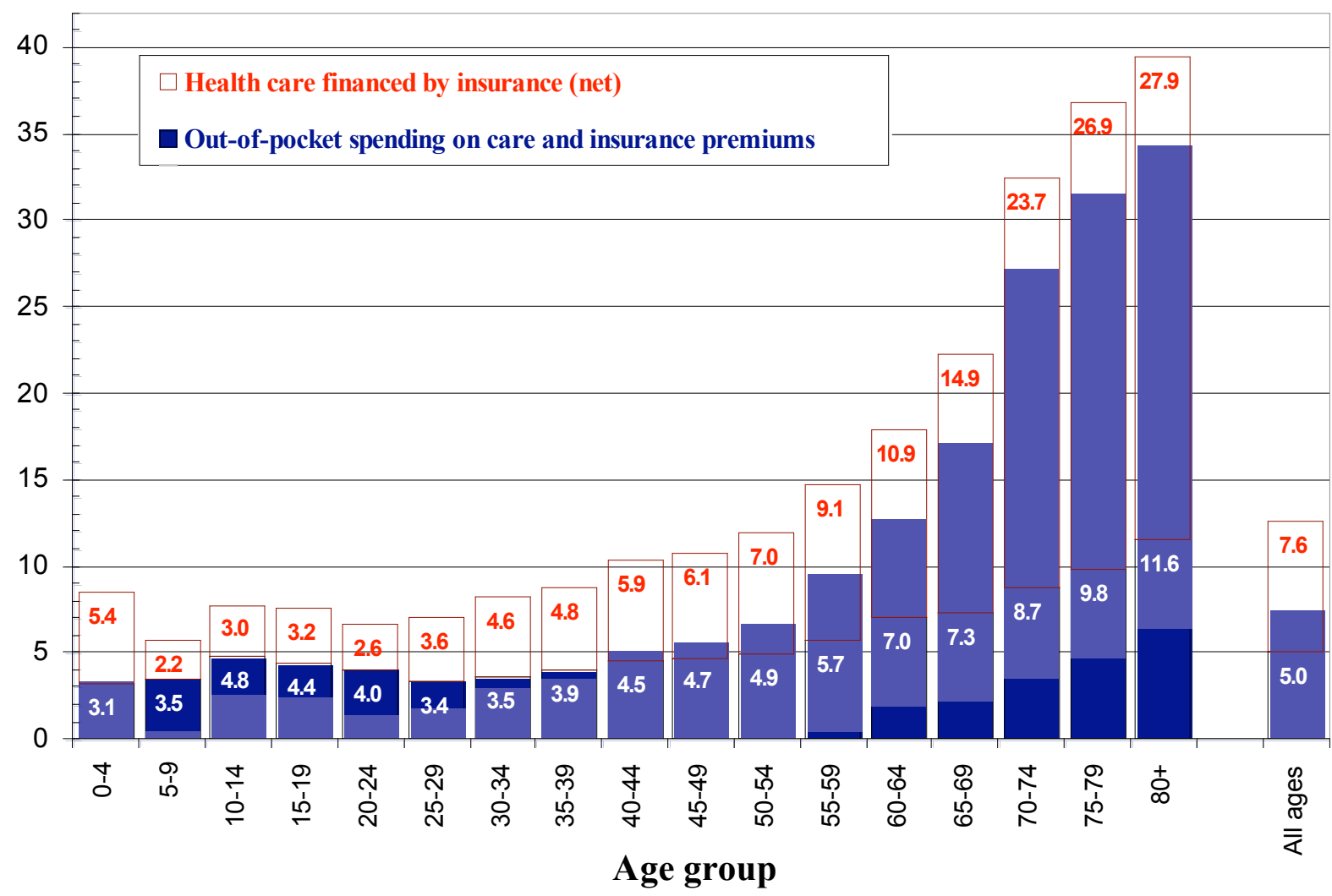

Source: Authors' tabulations of 2001-2005 MEPS household files. 
Figure 10. Total Health Care Expenditures by Fifth of the Income Distribution, 1996-2000 and 2001-2005

Total spending per person on health care:

Population under age 65

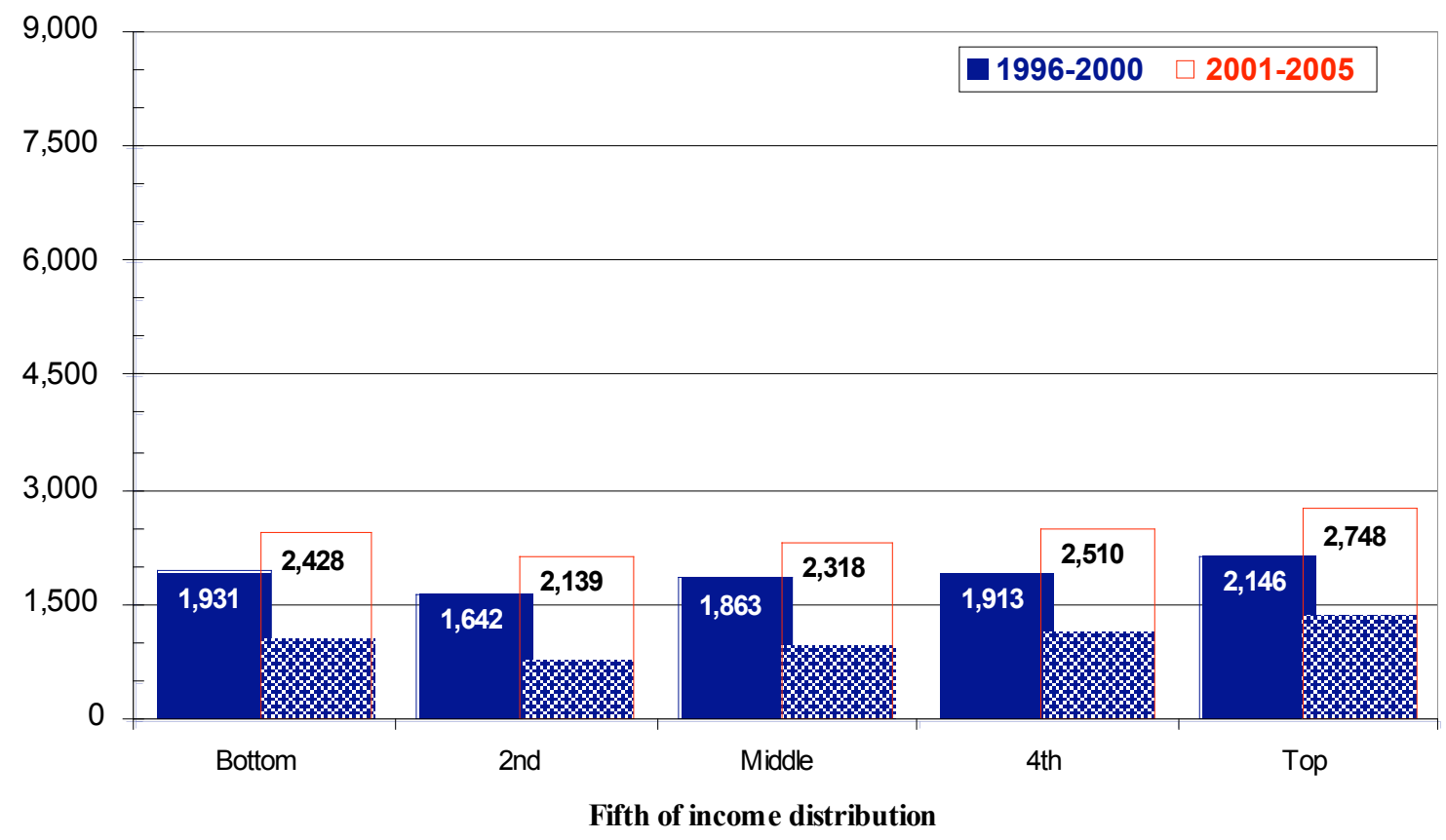

Total spending per person on health care:

Population age 65 and older

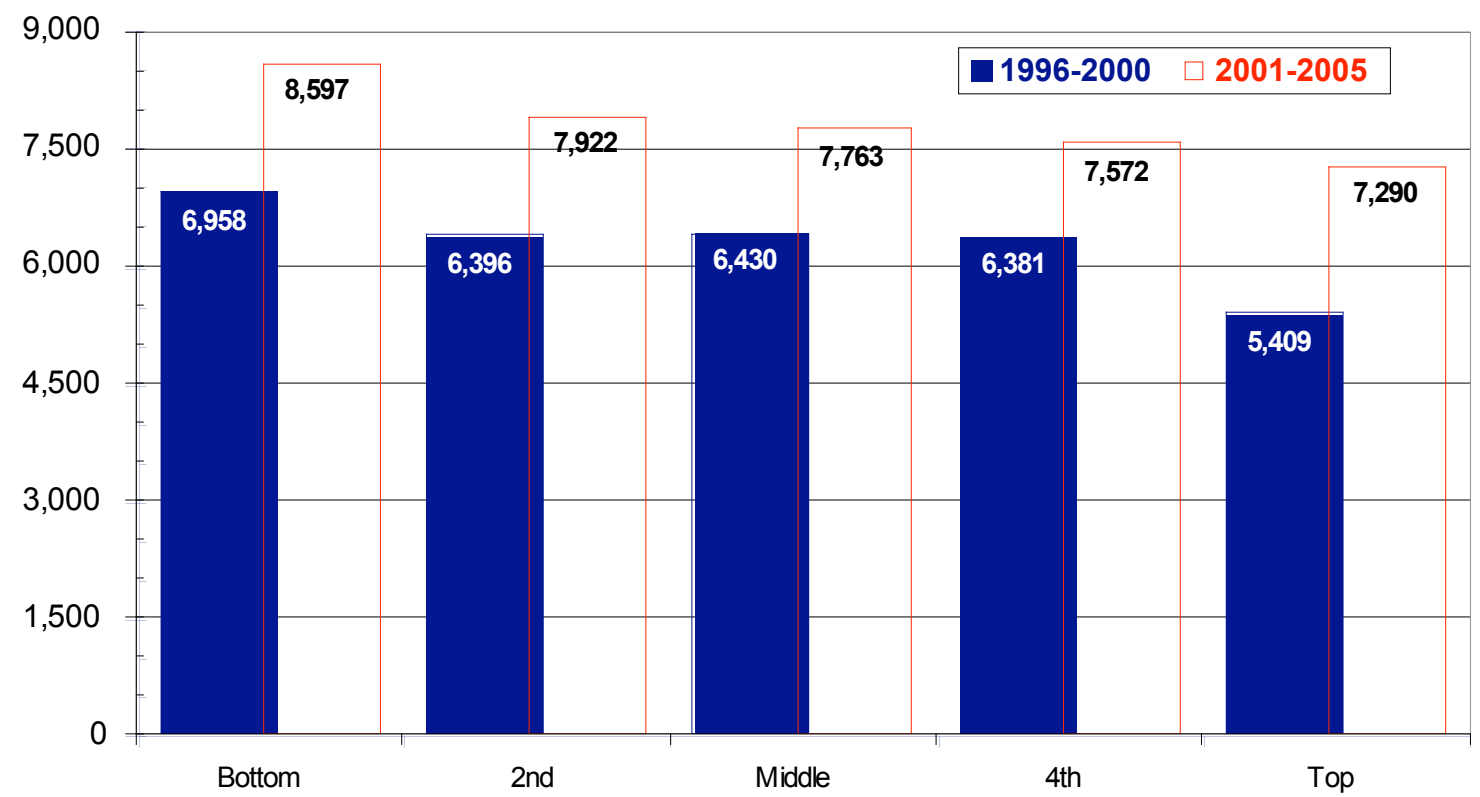

Fifth of income distribution

Note: Spending amounts are converted to 2005 dollars using the PCE deflator for medical goods and services.

Source: Authors' tabulations of 1996-2005 MEPS household files. 
Figure 11. Consumption and Financing of Health Care as a Percent of Gross Money Income by Position in the Income Distribution, 2001-2005

Spending on health care and insurance as percent of gross household income: Population under age 65

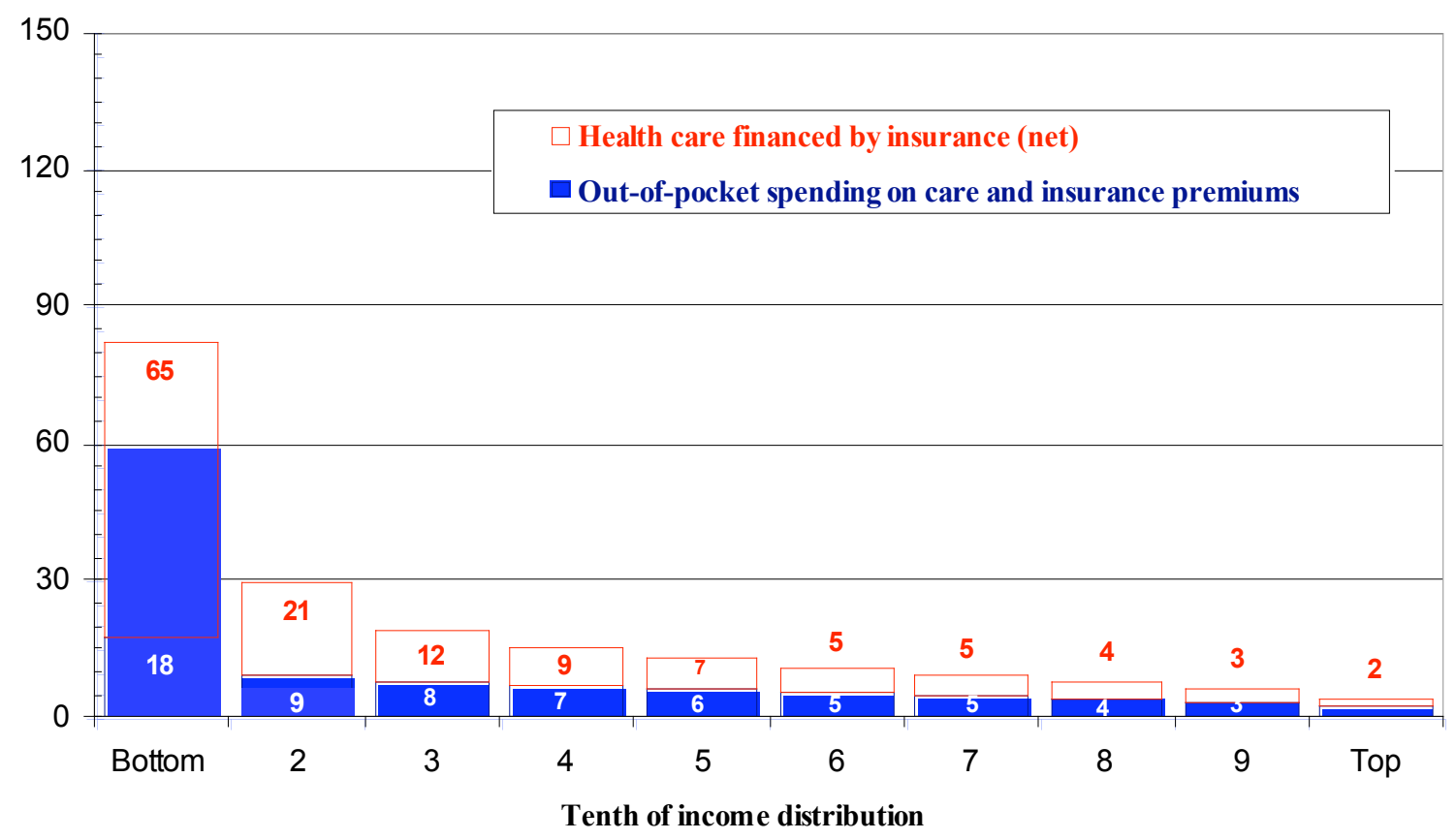

Spending on health care and insurance as percent of gross household income: Population age 65 and older

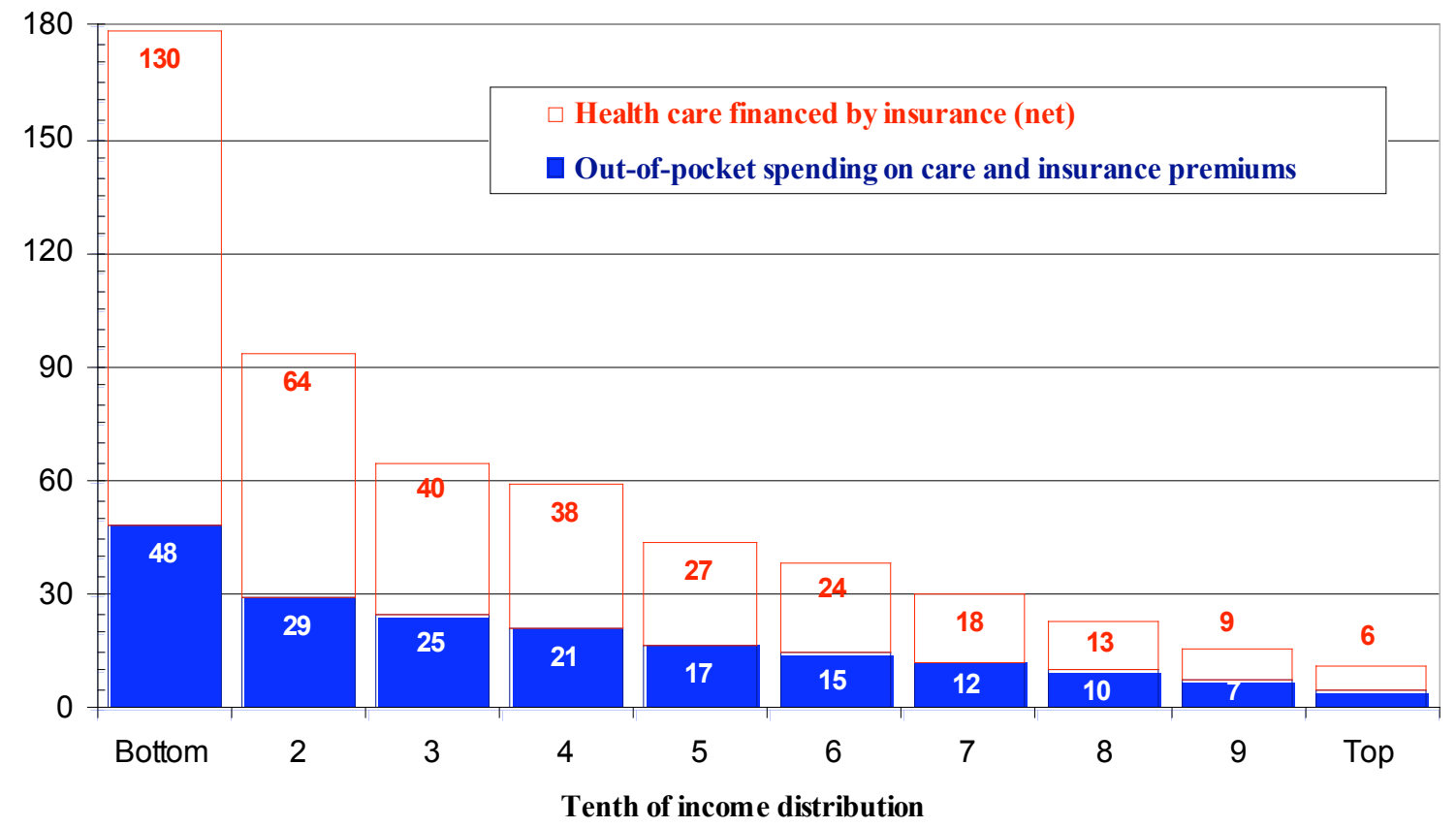

Source: Authors' tabulations of 2001-2005 MEPS household files. 
Figure 12. Age Distribution of Net gains from Health Insurance, 2001-2005

\begin{abstract}
Average size-adjusted income:
Constant 2005 dollars
\end{abstract}

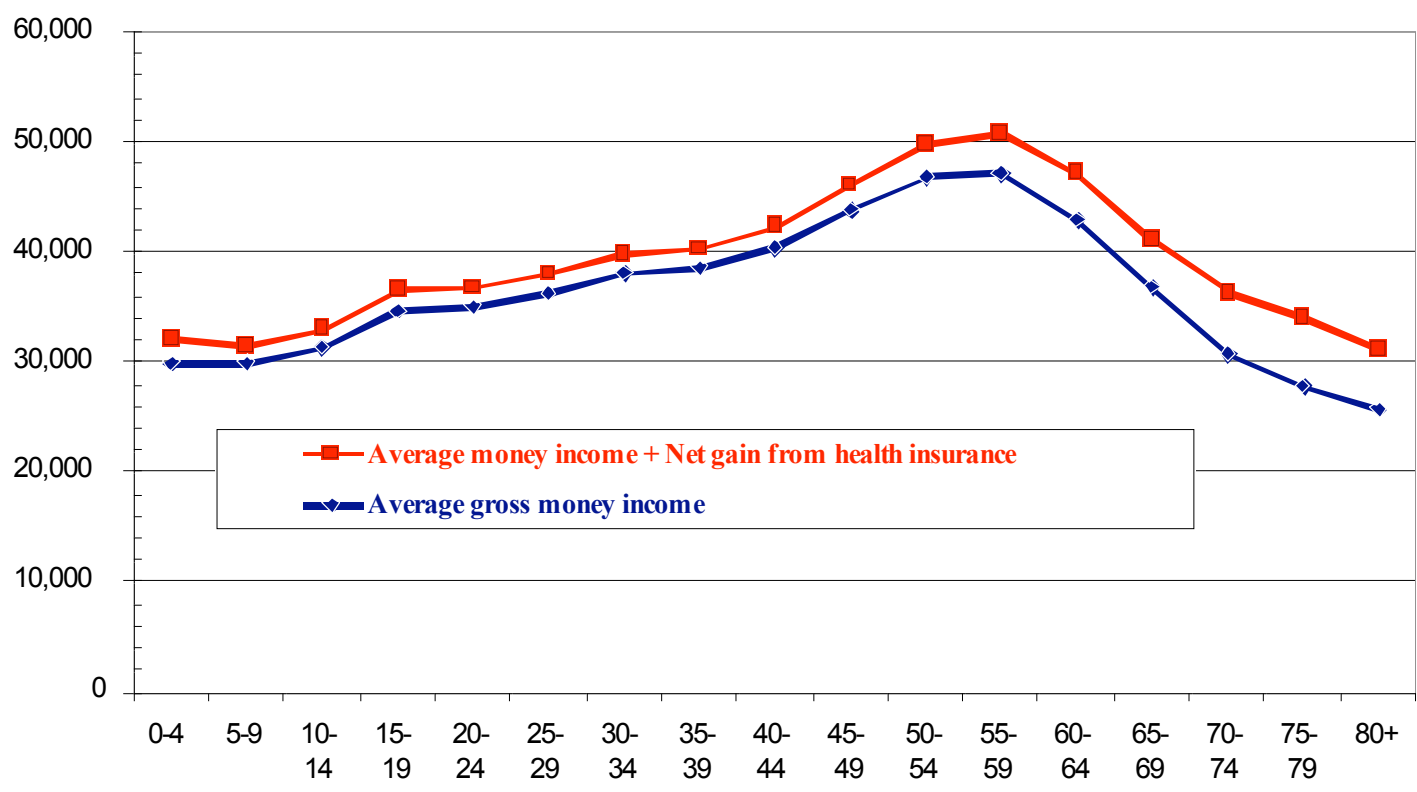

Age group

Net gain from health insurance per person:

Constant 2005 dollars

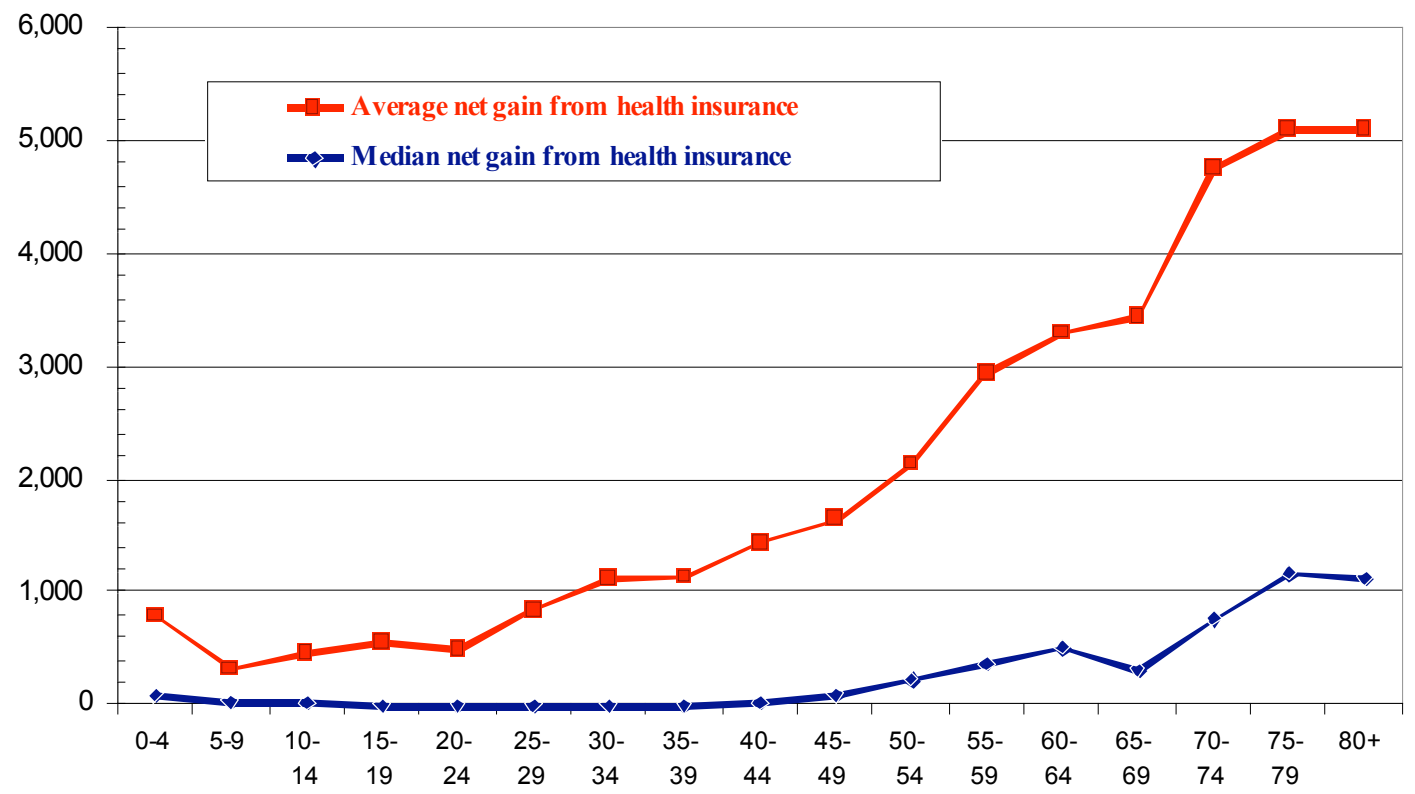

Age group

Note: All income,premium, reimbursement, and health spending amounts have been converted to constant 2005 dollars using the CPIU-RS deflator.

Source: Authors'tabulations of 2001-2005 MEPS household files. 
Figure 13. Rate of Decline in Income under Alternative Income Definitions between Ages 51 and 71, 2001-2005

Household-size-adjusted income

at age $51=100$

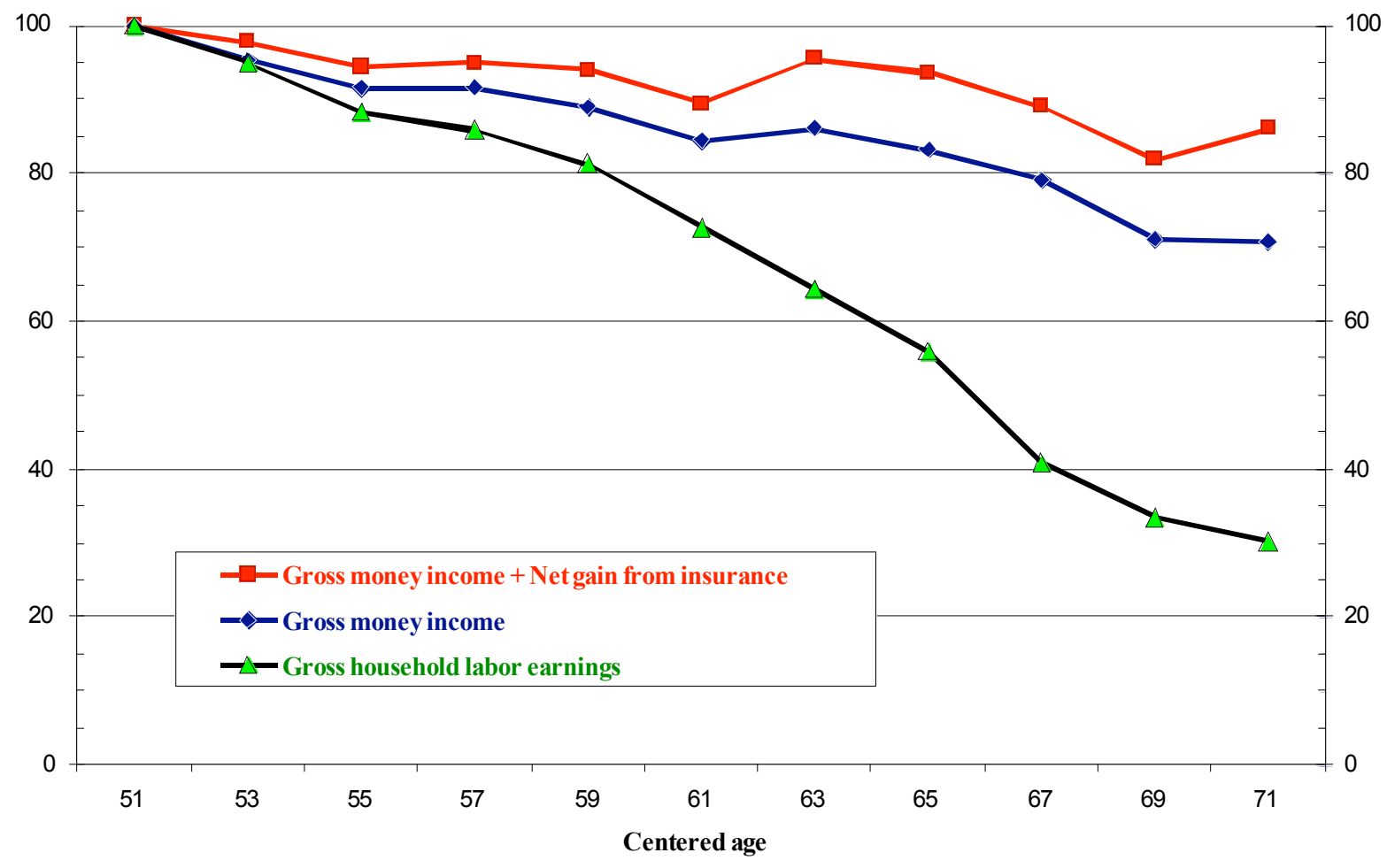

Note: In calculating rates of income decline, all income amounts were first adjusted to reflect differences in household size and then converted to constant 2005 dollars using the CPI-U-RS deflator.

Source: Authors' tabulations of the 2001-2005 MEPS household survey. 
Figure 14. Additions to Size-adjusted Money Income from Inclusion of Employer Insurance Contributions and Fungible Insurance Value by Age, 1996-2005

Percent of size-adjusted money income: 1996-2005 average

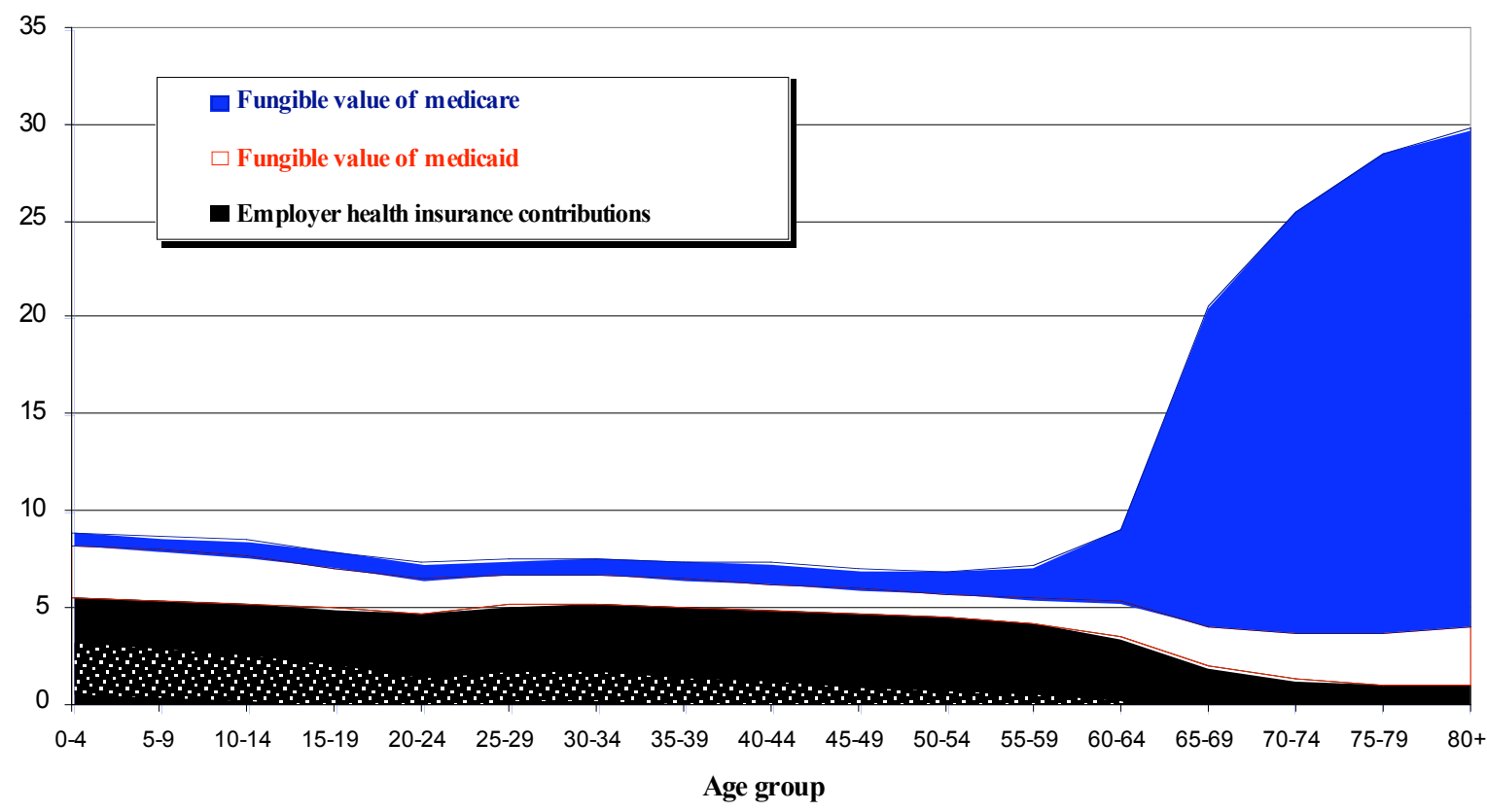

Percent of size-adjusted money income: 1996-2000 and 2001-2005

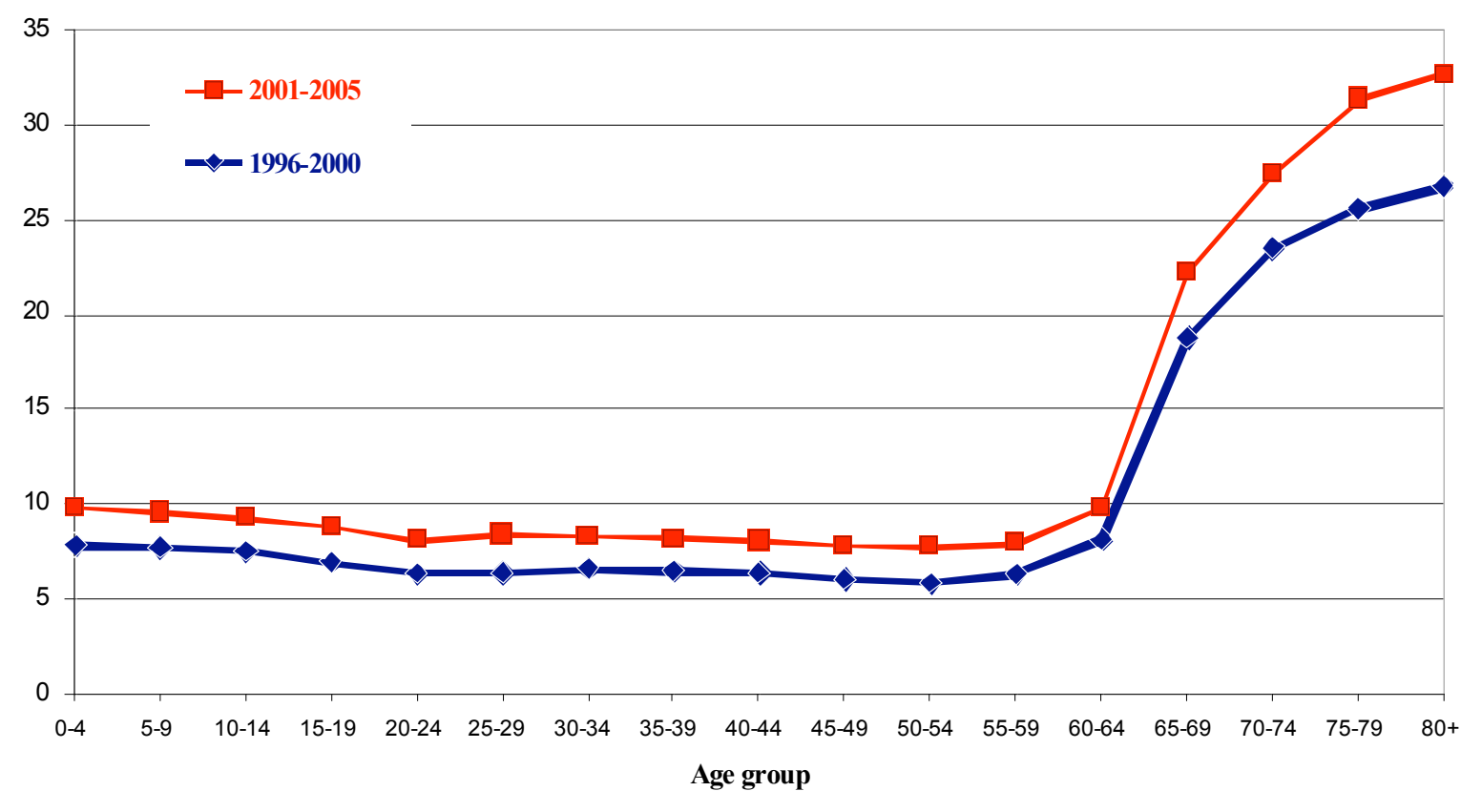

Source: Authors' tabulations of 1997-2006 March CPS files. 
Figure 15. Age Profile of Income under Alternative Income Definitions, 1996-2005

Population average income under definition $=100$

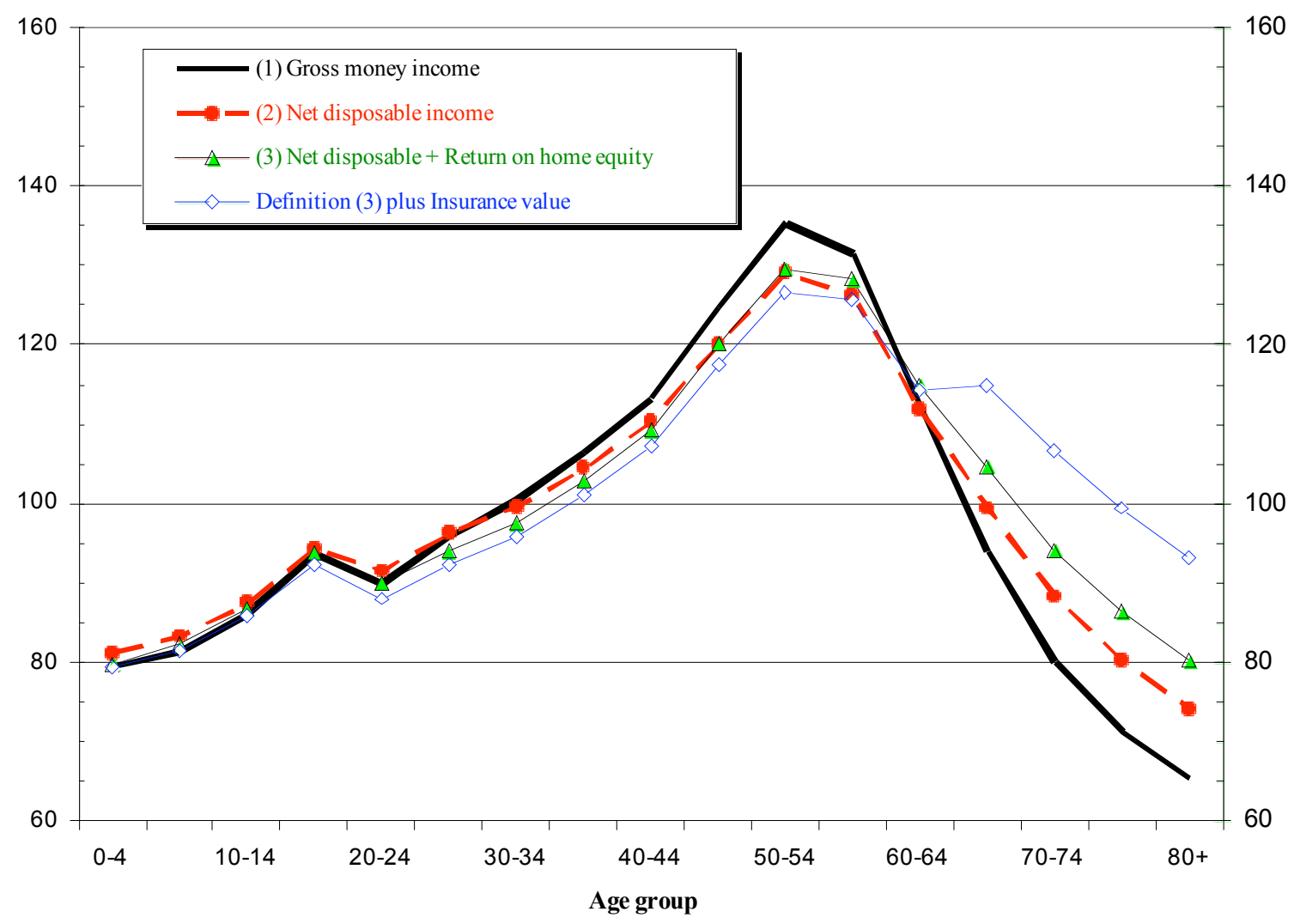

Note: All income amounts represent averages for the 1996-2005 period after conversion into constant 2005 dollars using the CPI-URS price deflator. The incomes of persons in each age group are 'equivalent' or household-size-adjusted incomes (see text).

Source: Authors' tabulations of 1997-2006 March CPS files. 
Figure 16. Alternative Estimates of the Contribution of Health Spending and Insurance Benefits to Personal Income in the CPS by Centile of the Income Distribution, 2001-2005

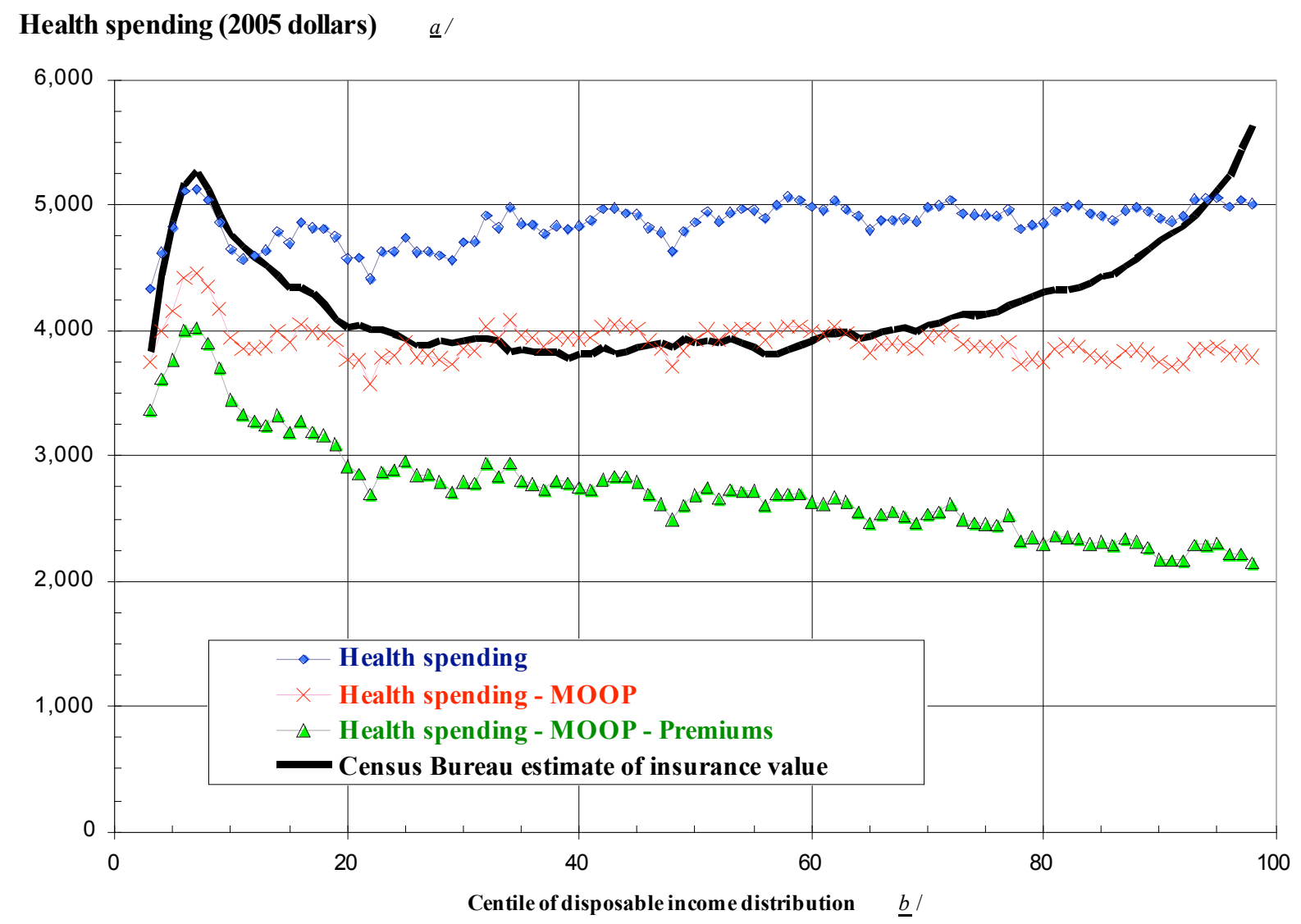

$a$ / Health spending estimates are statistical imputations from MEPS to households in the CPS file as described in the text. "MOOP" is medical out-of-pocket spending by household members on health goods and services. "Insurance value" estimates are Census Bureau imputations of the fungible insurance value of medicare and medicaid plus the imputed value of employer contributions to employee health plans. All health spending and insurance value amounts represent averages for calendar years 2001-2005 after spending amounts have been converted to 2005 dollars using the CPI-U-RS deflator. Spending amounts are adjusted to reflect differences in household size (see text).

$\underline{b}$ /Income is measured as gross money income plus near-cash transfer payments plus return on net equity in a home less income and payroll taxes. Income amounts are adjusted to reflect differences in household size (see text).

Source: Authors' tabulations of March CPS files containing income data for calendar years 2001-2005 and imputations from 20012005 MEPS household files. 


\section{RECENT WORKING PAPERS FROM THE}

\section{CENTER FOR RETIREMENT RESEARCH AT BOSTON COLLEGE}

\section{Do Health Problems Reduce Consumption at Older Ages?}

Barbara A. Butrica, Richard W. Johnson, and Gordon B.T. Mermin, March 2009

Financial Hardship Before and After Social Security's Early Eligibility Age

Richard W. Johnson and Gordon B.T. Mermin, March 2009

Rising Tides and Retirement: The Aggregate and Distributional Effects of Differential Wage Growth on Social Security

Melissa M. Favreault, March 2009

Accounting for the Heterogeneity in Retirement Wealth

Fang Yang, January 2009

Labor Supply Elasticity and Social Security Reform

Selahattin Imrohorolu and Sagiri Kitao, January 2009

Evaluating Micro-Survey Estimates of Wealth and Saving

Barry P. Bosworth and Rosanna Smart, January 2009

Portfolio Choice in Retirement: Health Risk and the Demand for Annuities, Housing, and Risky Assets

Motohiro Yogo, January 2009

The Disappearing Defined Benefit Pension and its Potential Impact on the Retirement Incomes of Boomers

Barbara A. Butrica, Howard M. Iams, Karen E. Smith, and Eric J. Toder, January 2009

Retirement and Social Security: A Time Series Approach

Brendan Cushing-Daniels and C. Eugene Steuerle, January 2009

Economic Restructuring and Retirement in Urban China

John Giles, January 2009

Sources of Support for Pension Reform: A Cross-National Perspective Michelle Dion and Andrew Roberts, January 2009

All working papers are available on the Center for Retirement Research website (http://www.bc.edu/crr) and can be requested by e-mail (crr@bc.edu) or phone (617-552-1762). 